\title{
MEN $\varepsilon / \beta$ nuclear-retained non-coding RNAs are up-regulated upon muscle differentiation and are essential components of paraspeckles
}

\author{
Hongjae Sunwoo, ${ }^{1}$ Marcel E. Dinger, ${ }^{2}$ Jeremy E. Wilusz, ${ }^{3}$ Paulo P. Amaral, ${ }^{2}$ \\ John S. Mattick, ${ }^{2}$ and David L. Spector ${ }^{1,3,4}$ \\ ${ }^{1}$ Molecular and Cellular Biology Graduate Program, Stony Brook University, Stony Brook, New York 11794 , USA; ${ }^{2}$ ARC Special \\ Research Centre for Functional and Applied Genomics, Institute for Molecular Bioscience, University of Queensland, St Lucia QLD \\ 4072, Australia; ${ }^{3}$ Watson School of Biological Sciences, Cold Spring Harbor Laboratory, Cold Spring Harbor, New York 11724, USA
}

\begin{abstract}
Studies of the transcriptional output of the human and mouse genomes have revealed that there are many more transcripts produced than can be accounted for by predicted protein-coding genes. Using a custom microarray, we have identified 184 non-coding RNAs that exhibit more than twofold up- or down-regulation upon differentiation of $\mathrm{C} 2 \mathrm{Cl} 2$ myoblasts into myotubes. Here, we focus on the Men $\varepsilon / \beta$ locus, which is up-regulated 3.3-fold during differentiation. Two non-coding RNA isoforms are produced from a single RNA polymerase II promoter, differing in the location of their 3' ends. Men $\varepsilon$ is a 3.2-kb polyadenylated RNA, whereas Men $\beta$ is an $\sim 20-k b$ transcript containing a genomically encoded poly(A)-rich tract at its $3^{\prime}$-end. The $3^{\prime}$-end of Men $\beta$ is generated by RNase $\mathrm{P}$ cleavage. The Men $\varepsilon / \beta$ transcripts are localized to nuclear paraspeckles and directly interact with NONO. Knockdown of $M E N \varepsilon / \beta$ expression results in the disruption of nuclear paraspeckles. Furthermore, the formation of paraspeckles, after release from transcriptional inhibition by DRB treatment, was suppressed in $M E N \varepsilon / \beta$-depleted cells. Our findings indicate that the $M E N \varepsilon / \beta$ non-coding RNAs are essential structural/organizational components of paraspeckles.
\end{abstract}

[Supplemental material is available online at www.genome.org.]

Sequencing of the human and other mammalian genomes has revealed the number of protein-coding genes to be in the range of 20,000-25,000 (Waterston et al. 2002; International Human Genome Sequencing Consortium 2004), representing $<2 \%$ of the total genomic sequence. However, recent studies of the mammalian transcriptome have shown that the majority of the genome is transcribed and that many transcripts lack protein-coding capacity (Carninci et al. 2005; Birney et al. 2007; Kapranov et al. 2007). Such analyses have prompted considerable discussion as to whether these non-coding RNAs (ncRNAs) simply represent transcriptional noise or are involved in cellular functions (for review, see Mattick and Makunin 2006). Interestingly, large-scale studies of ncRNAs have shown that many are dynamically regulated during differentiation and exhibit cell- and tissue-specific expression patterns (Ravasi et al. 2006; Dinger et al. 2008; Mercer et al. 2008). These observations support the contention that ncRNAs are likely to have functional roles in the cell, some of which may serve in regulatory and/or structural paradigms (for review, see Mattick 2004).

Although the number of ncRNAs identified has increased exponentially, very few ncRNAs have thus far been assigned a cellular function (for review, see Costa 2005; Prasanth and Spector 2007). Interestingly, several ncRNAs have been shown to be involved in the regulation of the transcriptional state of a locus or at the level of a single chromosome. For example, expression of the long ( $>100 \mathrm{~kb}$ ) ncRNA Airn (Antisense Igf2r RNA, also known as Air) is associated with silencing of the Igf2r, Slc22a2, and Slc22a3 genes in mice (Sleutels et al. 2002). In another case, it was sug-

${ }^{4}$ Corresponding author.

E-mail spector@cshl.edu; fax (516) 367-8876.

Article published online before print. Article and publication date are at http://www.genome.org/cgi/doi/10.1101/gr.087775.108. gested that the translocation of nuclear factor of activated $\mathrm{T}$ cells (NFAT) into the nucleus is repressed by non-coding repressor of NFAT (NRON) ncRNAs, a series of transcripts ranging in size between 0.8 and $3.7 \mathrm{~kb}$ (Willingham et al. 2005). In fission yeast, a recent report argued that transcription of ncRNAs at the promoter region can induce chromatin remodeling at the $f b p 1^{+}$locus (Hirota et al. 2008). Perhaps the best studied ncRNAs are Xist (Xinactive specific transcript) and Tsix (X inactive-specific transcript, antisense), key players in dosage compensation of the mammalian $\mathrm{X}$ chromosome. In females, Tsix is an antisense transcript of Xist, and its expression determines which $\mathrm{X}$ chromosome will be inactivated for dosage compensation (for review, see Heard and Disteche 2006; Erwin and Lee 2008). At the stage of X inactivation in mammalian development, Xist/XIST RNA, 15-17 kb in mouse and $\sim 19 \mathrm{~kb}$ in human, is transcribed from one of the two $\mathrm{X}$ chromosomes. This ncRNA subsequently coats the chromosome from which it is transcribed and represents part of the mechanism by which transcriptional inactivation of the coated chromosome is achieved (for review, see Plath et al. 2002; Heard and Disteche 2006).

In addition, several ncRNAs have been shown to be misregulated in various cancers (for review, see Costa 2005; Prasanth and Spector 2007). For example, elevated levels of the ncRNA MALAT1 (metastasis associated in lung adenocarcinoma transcript 1) were originally identified in individuals exhibiting a high risk for metastasis of non-small cell lung tumor (Ji et al. 2003). More recently, MALAT1 ncRNA was also shown to be present at higher levels in many other cancers, including uterine endometrial stromal carcinoma and hepatocellular carcinoma (Yamada et al. 2006; Lin et al. 2007). Increased expression of another ncRNA, PCA3 (prostate cancer antigen 3, also known as DD3), has been observed in individuals with prostate cancer (Bussemakers et al. 1999). Although the functions of these ncRNAs 
are not yet known, they may represent useful diagnostic markers in a large number of different cancers (for review, see Costa 2005; Prasanth and Spector 2007).

Determining the subcellular localization of ncRNAs is important for providing insights into their potential partners and the functional pathways with which they interact. The mammalian nucleus is a highly organized organelle with several membraneless subcompartments such as Cajal bodies, nucleoli, paraspeckles, PML bodies, and speckles, to name just a few (for review, see Spector 2001, 2006). Among them, paraspeckles were initially discovered via the identification and characterization of a paraspeckleassociated protein in a proteomic analysis of human nucleoli (Fox et al. 2002). Paraspeckles generally appear in clusters and are frequently localized in the nucleoplasm close to nuclear speckles, where pre-mRNA splicing factors are stored, assembled, and/or modified. Inhibition of RNA polymerase II transcription results in its protein components relocating to the periphery of nucleoli. As paraspeckles are sensitive to RNase A treatment (Fox et al. 2005; Prasanth et al. 2005), RNA(s) may be a critical component of this nuclear structure. Interestingly, Prasanth et al. (2005) identified Cat2-transcribed nuclear RNA (CTN-RNA), an $\sim 8$-kb transcript that is encoded by the $S l c 7 a 2$ (also known as $m C a t 2$, mouse cationic amino acid transporter 2) gene and is retained in the nucleus in paraspeckles. CTN-RNA is produced via utilization of an alternative promoter coupled with the utilization of the distal-most polyadenylation site, resulting in an extended $3^{\prime}$-UTR. Upon stress, CTN-RNA is cleaved, releasing the upstream Slc7a2 open reading frame (ORF) such that it can transit to the cytoplasm to be translated (Prasanth et al. 2005). By cleaving the "stored" nuclearretained RNA and bypassing the need for initiating Slc7a2 transcription during stress, the nuclear-retained form of this RNA represents a rapid response mechanism for gene expression. Although representing an RNA component of paraspeckles, knockdown of CTN-RNA does not result in any change in the morphology of paraspeckles, suggesting that it does not confer any structural integrity to this nuclear domain (Prasanth et al. 2005). Therefore, although paraspeckles are sensitive to RNase A treatment, thus far, a specific RNA(s) involved in its structural integrity has not been identified.

In the present study, we used a custom microarray to identify ncRNAs that exhibit altered levels upon C2C12 myoblast differentiation into myotubes. One of the identified loci, the Men1 (multiple endocrine neoplasia 1) locus on mouse chromosome $19 \mathrm{qA}$, exhibited a 3.3-fold increased level of RNA in myotubes versus myoblasts. This locus produces two ncRNA isoforms: the mouse Men epsilon $(\varepsilon)$ transcript is $3.2 \mathrm{~kb}$ and the Men beta $(\beta)$ transcript is $\sim 20 \mathrm{~kb}$ in length. Recently, this locus was also shown to be up-regulated during bovine muscle development (Lehnert et al. 2007). RNA fluorescence in situ hybridization (FISH) revealed that these transcripts exhibit a punctate pattern in the nucleus that corresponds to paraspeckles. This distribution is consistent with a previous report of these RNAs localizing adjacent to nuclear speckles (Hutchinson et al. 2007). Interestingly, the Men $\varepsilon / \beta$ transcripts directly interact with the NONO (also known as p54/ nrb) complex, a known protein component of paraspeckles. Knockdown of these RNAs induced the disruption of paraspeckles, suggesting that the MEN $\varepsilon / \beta$ transcripts are essential for the structural/organizational integrity of this nuclear domain. In addition, inhibition of RNA polymerase II transcription resulted in a redistribution of PSPC1 (also known as PSP1 $\alpha$ ) as well as the MEN $\varepsilon / \beta$ transcripts without altering the level of these ncRNAs or protein, indicating that active transcription of the $M E N \varepsilon / \beta$ locus is required to establish paraspeckles. In summary, we have identified a ncRNA locus that is up-regulated upon myoblast to myotube differentiation and whose RNA products are critical structural/organizational components of paraspeckles.

\section{Results}

\section{Identification of ncRNAs that are differentially expressed upon myoblast differentiation into myotubes}

We used a custom microarray to examine the expression profiles of 4694 non-coding and 13,432 protein-coding RNAs during myoblast differentiation. RNA was isolated from C2C12 myoblasts at three stages of differentiation: $50 \%$ confluent myoblasts, $24 \mathrm{~h}$ post-induction, and $5 \mathrm{~d}$ post-induction, where the cells appear predominantly as fully differentiated myotubes (see Methods). Across the three stages of differentiation, 8442 coding and 1425 non-coding transcripts were expressed above background, and of these, respectively, $1814(21.5 \%)$ and $184(13.0 \%)$ were significantly differentially expressed (fold-change $>2 ; B$-statistic $>3$ ) (Supplemental Table 1).

After the 184 ncRNA candidates were manually examined in terms of overall expression levels, extent of differential expression, and the possibility of overlapping with any known proteincoding genes, 14 full-length ncRNA gene loci were selected for subcellular localization studies. One of these, AK028745, showed a distinct punctate distribution in the nuclei of $\mathrm{C} 2 \mathrm{C} 12$ myoblast cells (Fig. 1A). Interestingly, this RNA exhibited a similar localization pattern in several mouse and human cell lines (Supplemental Fig. 1). Upon differentiation of myoblasts to myotubes, this RNA was present at a 3.3-fold higher level based on our microarray analysis (Supplemental Table 1). These punctate foci were enlarged and more abundant in myotube nuclei compared to myoblast nuclei, consistent with the increased levels observed in our microarray results (Fig. 1B). To further confirm our microarray results, Q-PCR was performed (Fig. 1C) using several primer sets around the mapped position of EST clone AK028745 (Men $\varepsilon / \beta$ locus) (see Fig. 2A for primer positions). While primers targeted upstream of the AK028745 promoter failed to amplify a product as expected, primers to the non-coding transcripts showed that the expression of this locus increased 3.2-4.9-fold upon differentiation of myoblasts to myotubes (Fig. 1C). As described below, two ncRNAs (Men $\varepsilon$ and Men $\beta$ ) are generated from this locus, and the expression of both transcripts increases upon differentiation.

\section{Two long non-coding RNAs are generated from the Men $\varepsilon / \beta$ locus}

EST clone AK028745 corresponds to a 3.2-kb ncRNA known as Men $\varepsilon$ (also known as Neat1) (Hutchinson et al. 2007) that maps to an intergenic region on mouse chromosome 19qA (Fig. 2A). No known genes are located within $20 \mathrm{~kb}$ downstream from the $3^{\prime}$ end of Men $\beta$, a longer isoform of Men $\varepsilon$, although the proteincoding gene Frmd8 is located $<6 \mathrm{~kb}$ upstream of the $5^{\prime}$ end of Men $\varepsilon$. RNA FISH analysis using a probe to the coding region of Frmd8 did not reveal a nuclear punctate pattern, implying that Men $\varepsilon$ is not an unannotated exon of Frmd8 (data not shown). Instead, Men $\varepsilon$ is transcribed from a separate transcriptional unit that has a CpG island in its promoter region (Fig. 2A). The Men $\varepsilon$ transcript is unspliced, polyadenylated, lacks repetitive elements, and is highly conserved among mouse, rat, and human

\section{Genome Research}


(Fig. 2A). 5'- and 3'-RACE were used to confirm the previously annotated ends of the 3.2-kb Men $\varepsilon$ transcript (Hutchinson et al. 2007; data not shown). By Northern blot analysis, we determined

A
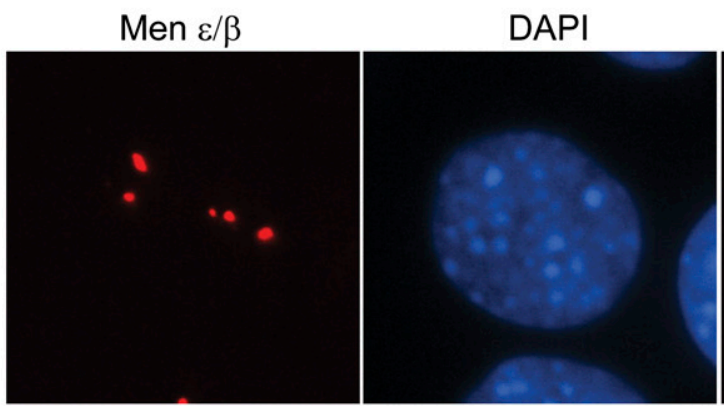

B
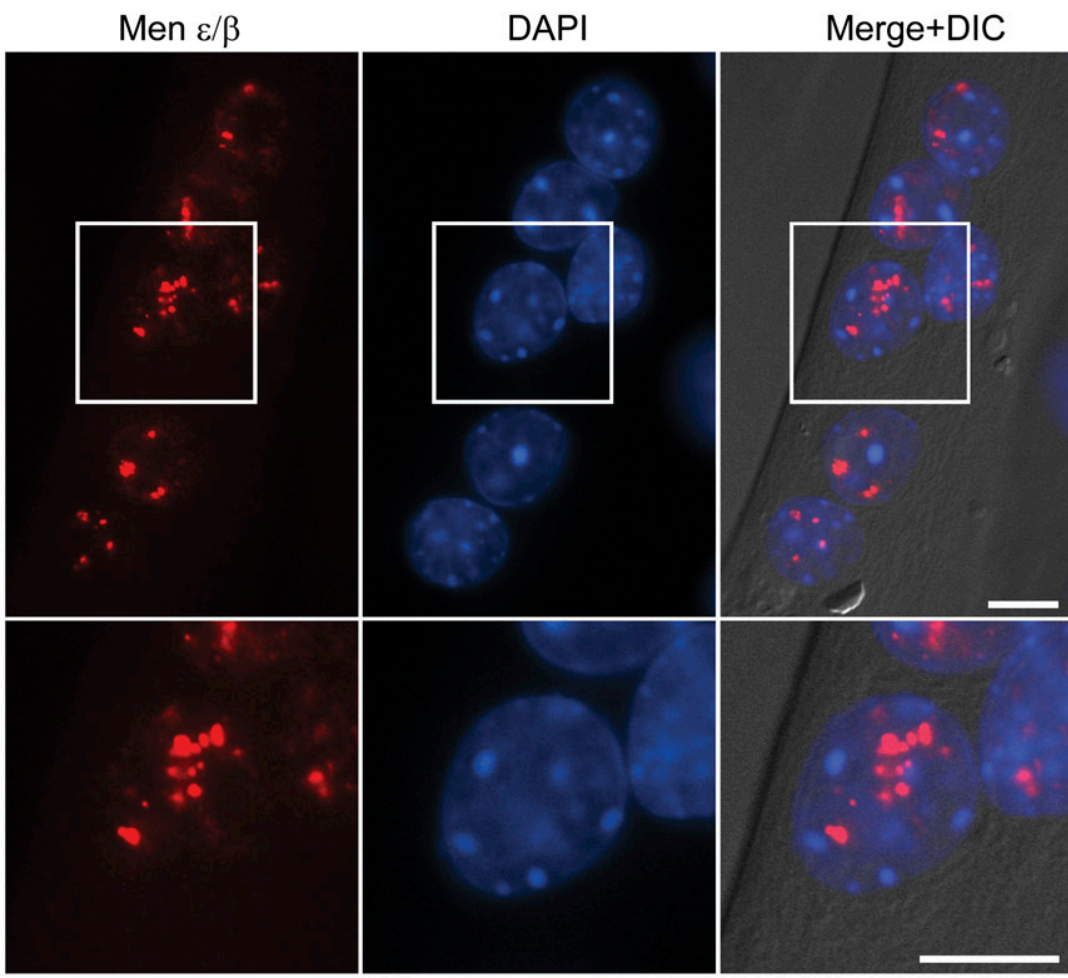

C

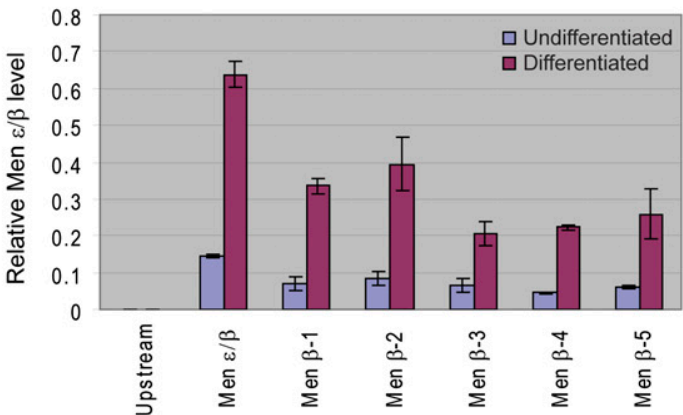

Figure 1. Men $\varepsilon / \beta$ ncRNA localization in $\mathrm{C} 2 \mathrm{C} 12$ nuclei. ( $A$ ) RNA FISH revealed that the Men $\varepsilon / \beta$ transcripts are localized in discrete foci in $\mathrm{C} 2 \mathrm{C} 12$ myoblast nuclei. (B) In $\mathrm{C} 2 \mathrm{C} 12$ myotubes, the foci of Men $\varepsilon / \beta$ ncRNAs are enlarged and present in greater numbers than in $C 2 C 12$ myoblasts. Scale bars, 10 $\mu \mathrm{m}$. (C) Both Men $\varepsilon$ and Men $\beta$ isoforms are up-regulated upon $\mathrm{C} 2 \mathrm{C} 12$ myoblast differentiation into myotubes as assessed by Q-PCR. Gapdh was used as a normalization control. The data in the histogram are shown as mean and standard deviation values of three independent experiments. that Men $\varepsilon$ is broadly expressed in many mouse tissues (Fig. 2B). The highest Men $\varepsilon$ transcript levels were observed in kidney and lung (Fig. 2B).

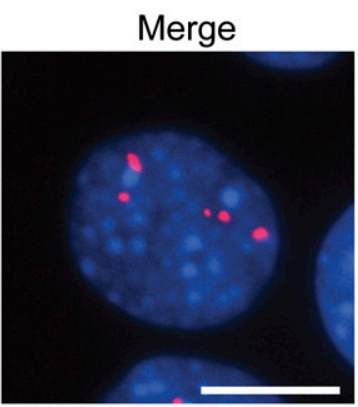

The human ortholog MEN $\varepsilon$ was previously identified as one of several transcripts produced from the MEN1 locus on human chromosome 11q13.1 (Guru et al. 1997). In addition to the 3.7kb polyadenylated human $M E N \varepsilon$, a longer transcript $M E N \beta$ was also previously identified (Guru et al. 1997). MEN $\varepsilon$ and $M E N \beta$ share the same RNA polymerase II promoter, but differ in the location of their 3' ends. Upon analyzing the many human EST clones mapping to this genomic region, we determined that human $M E N \beta$ is an $\sim 23-\mathrm{kb}$ unspliced transcript that contains many repetitive elements (Supplemental Fig. 2A). In contrast, there are only a few EST clones that map in a discontinuous manner to the mouse Men $\beta$ genomic region (Fig. 2A), and it has been previously argued that the mouse Men $\beta$ isoform is not transcribed (Hutchinson et al. 2007). However, it was recently shown that transcriptional elongation marks (H3K36me3) extend through the Men $\beta$ locus in mouse embryonic stem cells (Mikkelsen et al. 2007), where the Men $\varepsilon / \beta$ ncRNAs are expressed (Dinger et al. 2008; data not shown). Indeed, we were able to detect expression of the $\sim 20$-kb mouse Men $\beta$ transcript in C2C12 myoblast cells by RNA FISH (Supplemental Fig. 2) and RT-PCR (data not shown). The tissue expression profile of the mouse Men $\beta$ transcript was examined by an RNase protection assay (Fig. 2C). Like Men $\varepsilon$, Men $\beta$ was broadly detected in mouse tissues, with the highest Men $\beta$ transcript levels in colon and ovary (Fig. 2C).

An annotated human microRNA, miR-612, maps near the 3 ' end of the MEN $\beta$ transcript, suggesting that MEN $\beta$ may function as a microRNA precursor. However, miR-612 is poorly conserved and has not previously been detected in mouse cells. In addition, we failed to detect human miR-612 expression by Northern blot analysis (data not shown), suggesting that miR-612 may be misannotated and that $M E N \beta$ is not likely a microRNA precursor.

\section{The $3^{\prime}$ end of Men $\beta$ is generated} by RNase $P$

MEN $\beta$ was originally suggested to be an alternative polyadenylation isoform of MEN $\varepsilon$ (Guru et al. 1997). By Northern 
A

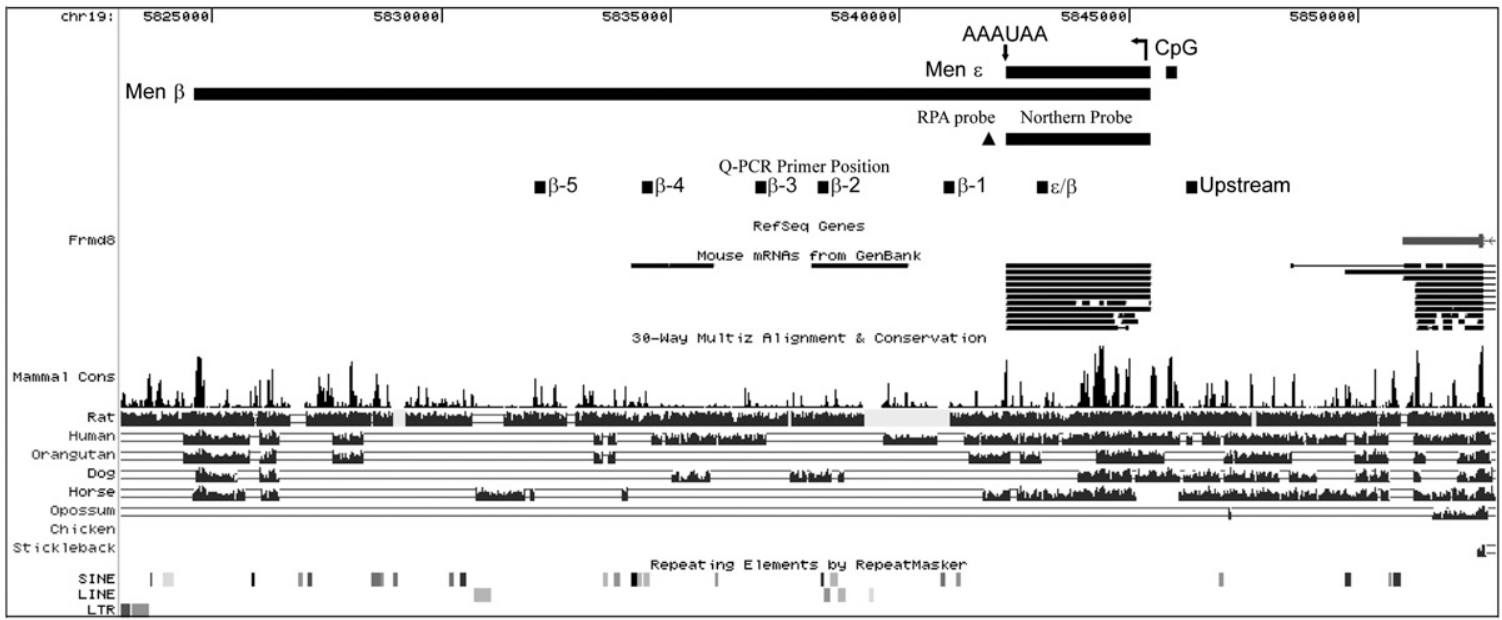

B

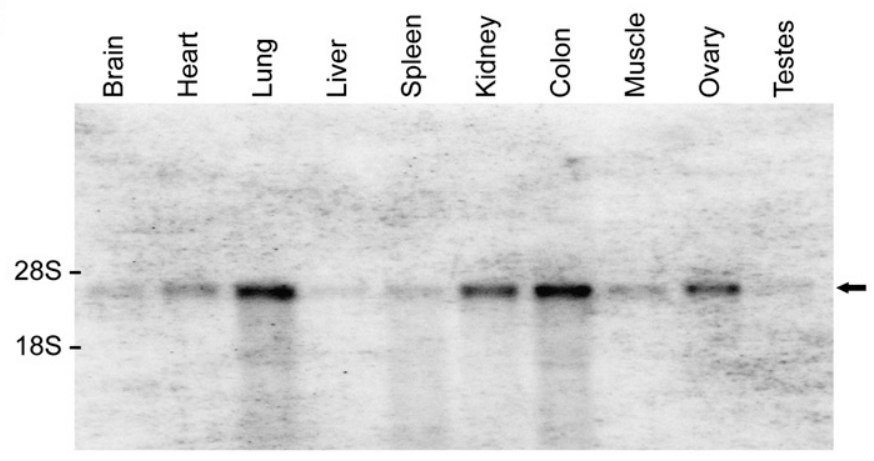

$\beta$-Actin
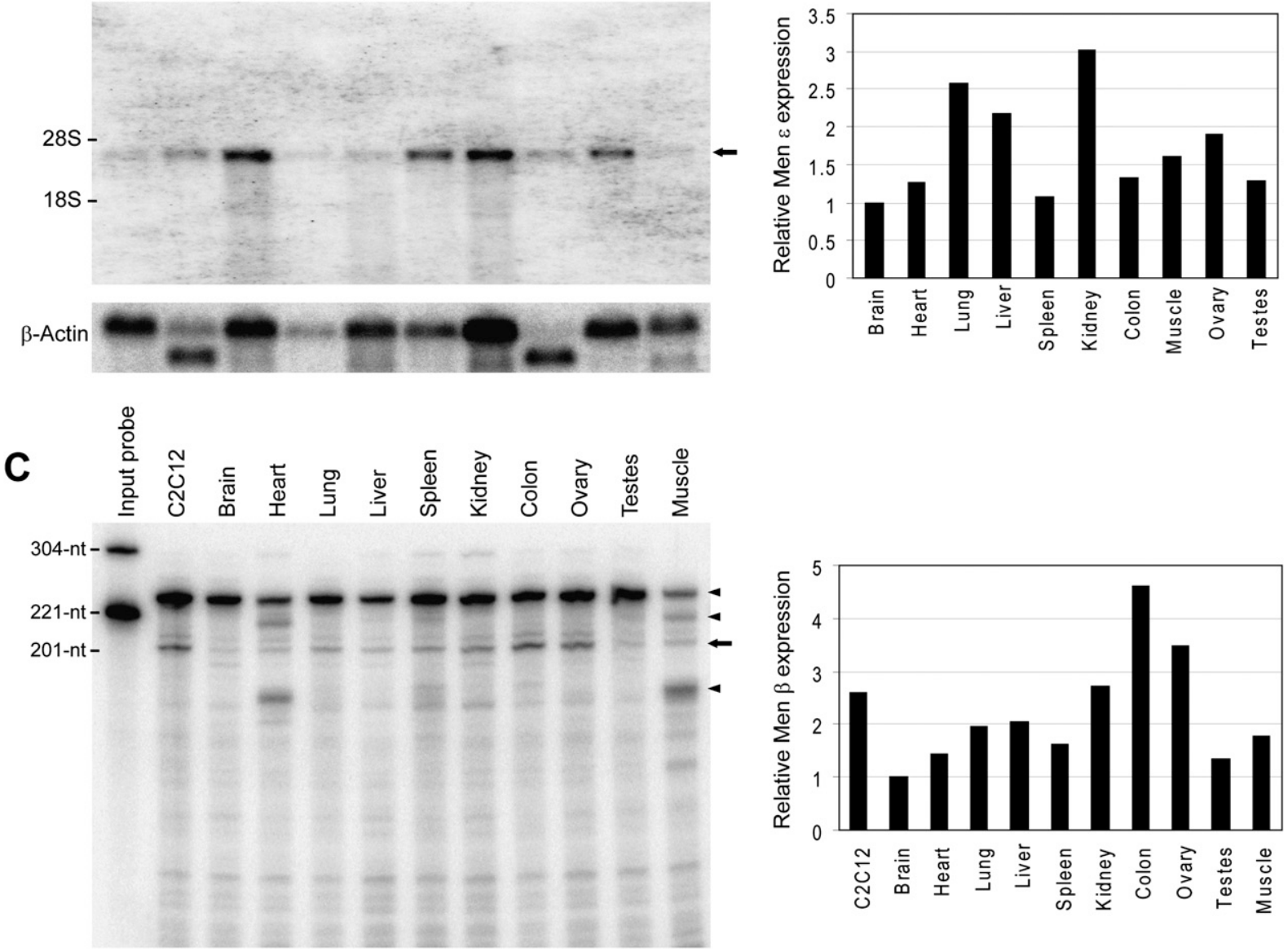

Figure 2. The Men $\varepsilon / \beta$ locus produces two non-coding RNAs. ( $A$ ) The Men $\varepsilon / \beta$ ncRNAs are transcribed from a single promoter located on mouse chromosome $19 \mathrm{qA}$. Men $\varepsilon$ is highly conserved among mammals and does not contain any repetitive elements. (Arrows) Transcription start site and polyadenylation site. (Black box) Northern and ( $\mathbf{\Lambda})$ RNase protection assay (RPA) probe positions. The position of the primer pairs used in the Q-PCR (Fig. 1C) is indicated. The $3^{\prime}$-UTR of a nearby protein coding gene is located $\sim 6 \mathrm{~kb}$ upstream of the transcription start site. (B) Northern blot analysis using 10 $\mu \mathrm{g}$ of total RNA from 8-wk-old C57BL6 mice. (Arrow) A single band of $\sim 3.2 \mathrm{~kb}$ was detected using a probe complementary to the Men $\varepsilon$ transcript. Relative levels of Men $\varepsilon$ in various tissues are depicted as a histogram. Beta-actin (also known as Actb) was used as a loading control. (C) An RNase protection assay was performed using $10 \mu \mathrm{g}$ of total RNA from the same mice. Relative levels of Men $\beta$ in various tissues are depicted as a histogram. Betaactin was used as a loading control. The full-length beta-actin probe and Men $\beta$ probe are $304 \mathrm{nt}$ and $221 \mathrm{nt}$, respectively. (Arrow) The protected MEN $\beta$ fragment is $201 \mathrm{nt}$. (Arrowheads) Protected beta-actin fragments, 245-nt major fragment, and two smaller muscle-specific fragments. 
blot analysis using multiple probes, we were able to detect MEN $\beta$ expression in HeLa cells and roughly define the location of its $3^{\prime}$ end (Fig. 3A). Surprisingly, there are no canonical cleavage/ polyadenylation signals located in the immediate vicinity of where $M E N \beta$ ends (Fig. 3C; Supplemental Fig. 3), suggesting that the 3 '-end of MEN $\beta$ is generated via a different mechanism. Indeed, when we carried out RNase $\mathrm{H}$ digestion followed by Northern blot analysis to better define the 3 '-end of $M E N \beta$, it was determined that MEN $\beta$ 3'-end cleavage occurs at a defined nucleotide position and that there is no subsequent addition of nucleotides as occurs during polyadenylation (Fig. 3B). Rather than a classical poly(A) tail, the mature $M E N \beta$ transcript has a short poly(A)-rich tract at its $3^{\prime}$-end, which is genomically encoded (Fig. 3C).
Upon searching the human and mouse genomes for sequences similar to the $3^{\prime}$-end of $M E N \beta$, we found that it is similar to the 3'-end of MALAT1 (Supplemental Fig. 3). We have recently shown that the 3 '-end of the abundant Malat 1 transcript is not generated by a classical cleavage/polyadenylation mechanism, but is instead generated by RNase P (Wilusz et al. 2008). A tRNA-like structure present within the primary Malat1 transcript is recognized by RNase $\mathrm{P}$, allowing the enzyme to cleave and generate the 3 '-terminus of the mature Malat1 transcript (Wilusz et al. 2008). A similar evolutionarily conserved tRNA-like structure is present at the $3^{\prime}$-end of the $M E N \beta /$ Men $\beta$ locus (Supplemental Figs. 3,4 ). To test if RNase P generates the mature 3 '-end of the Men $\beta$ transcript, a 189-nt region encompassing the 3 '-end of Men $\beta$ was cloned, transcribed in vitro, and employed for
A

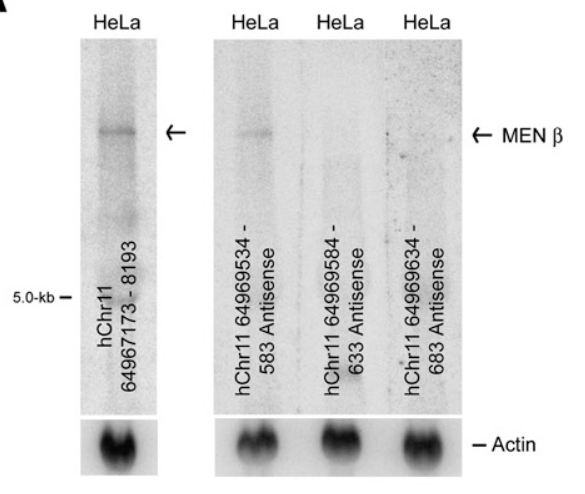

C
B

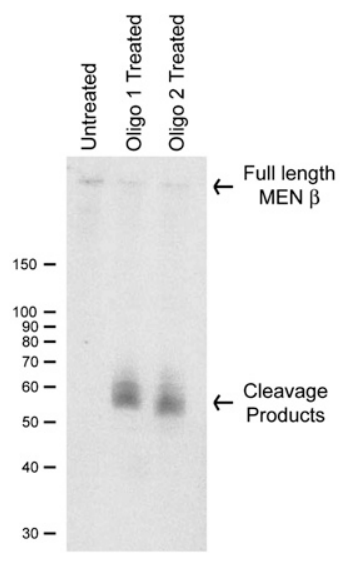

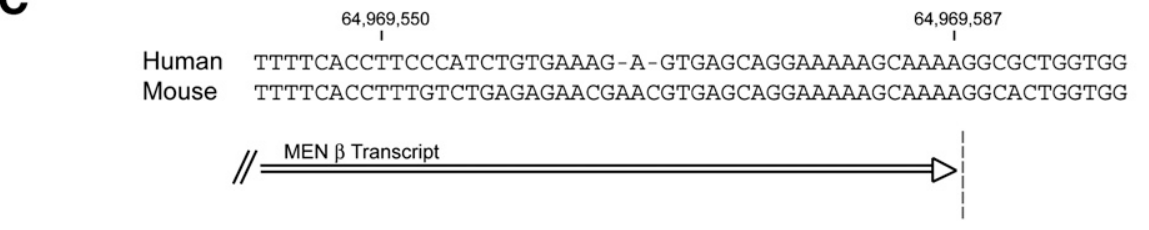

D

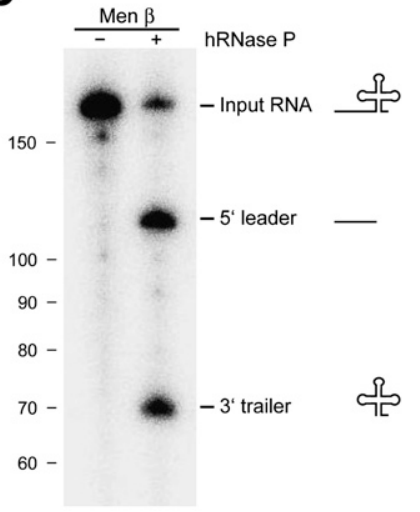

$\mathbf{E}$

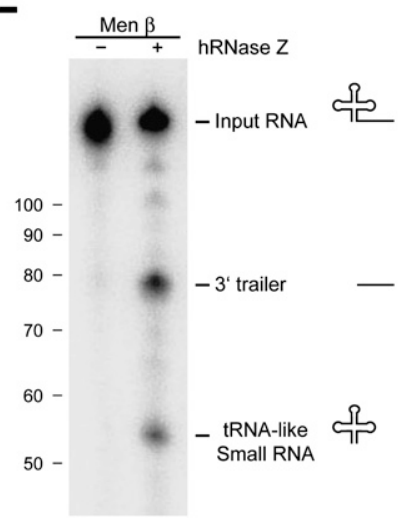

F

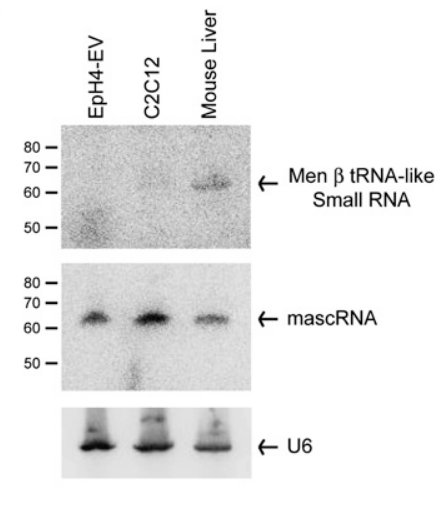

Figure 3. RNase $\mathrm{P}$ cleavage generates the $3^{\prime}$ end of Men $\beta$. (A) Northern blot analysis using $20 \mu \mathrm{g}$ of total RNA showed that the human $M E N \beta$ ortholog is expressed in (left) HeLa cells. The designated oligonucleotide probes were then used to roughly map (right) the $3^{\prime}$ end of MEN $\beta$. Beta-actin was used as a loading control. (B) RNase H digestion followed by Northern blot analysis was used to more finely map the $3^{\prime}$ end of MEN $\beta$. Oligo 1 is complementary to nucleotides $64,969,484-64,969,533$ of human chromosome 11 . Oligo 2 is complementary to nucleotides $64,969,492-64,969,541$ of human chromosome 11. (C) The in vitro RNase P cleavage site, which corresponds to the $3^{\prime}$ end of the mature MEN $\beta$ transcript, was mapped by ligation-based RNA cloning procedures. Numbers at the top indicate the position on human chromosome 11. $(D)$ Men $\beta$ is a substrate for human RNase P. $(E)$ Recombinant His-tagged human RNase Z cleaves Men $\beta$ in vitro. ( $F$ ) Northern blot analysis using $25 \mu \mathrm{g}$ of total RNA from EpH4-EV, C2C12, or mouse liver showed that the Men $\beta$ tRNA-like small RNA is selectively stabilized in liver. U6 was used as a loading control. 
RNase $P$ in vitro cleavage assays. Partially purified human RNase $\mathrm{P}$ was able to cleave Men $\beta$ in vitro at the expected 3 '-end of mature Men $\beta$, showing that the in vitro system accurately recapitulates in vivo Men $\beta$ processing (Fig. 3D). The Malat1 tRNA-like structure is further cleaved by RNase $\mathrm{Z}$ at its $3^{\prime}$-end to yield a 61-nt tRNA-like transcript named mascRNA (Malat1-associated small cytoplasmic RNA) (Wilusz et al. 2008). The Men $\beta$ tRNA-like structure can similarly be cleaved in vitro by recombinant human RNase $Z$ (Fig. 3E), suggesting that 3 '-end processing of the Men $\beta$ transcript also yields a small tRNA-like transcript. While mascRNA is broadly expressed in tissues and cell lines (Fig. 3F; Wilusz et al. 2008), the MEN $\beta$ /Men $\beta$ tRNA-like small RNA generally fails to accumulate to significant steadystate levels. By Northern blot analysis, we were unable to detect expression of the MEN $\beta$ /Men $\beta$ tRNA-like small RNA in C2C12, EpH4-EV, or HeLa cells (Fig. 3F; data not shown), but were able to detect expression in mouse liver. These data suggest that the MEN $\beta$ /Men $\beta$ tRNA-like small RNA may be selectively stabilized in a cell-type-specific manner.

\section{Men $\varepsilon / \beta$ ncRNAs are localized to nuclear paraspeckles}

The observed punctate distribution of Men $\varepsilon / \beta$ ncRNAs was further examined to assess its colocalization with known nuclear domains. We found that Men $\varepsilon / \beta$ and MEN $\varepsilon / \beta$ ncRNAs are not enriched in PML bodies, Cajal bodies, or nuclear speckles in mouse or most human cells (Supplemental Fig. 5). Only in HeLa cells, among cells examined, the MEN $\varepsilon$ transcripts exhibited a punctate distribution as well as a less intense speckle localization (Supplemental Fig. 5B). However, consistent with the results of a recent study (Hutchinson et al. 2007), MEN $\varepsilon / \beta$ commonly localize in domains that are adjacent to nuclear speckles, suggesting that they may be constituents of paraspeckles. We established a C2C12 cell line stably expressing PSPC1 (also known as PSP1 $\alpha$ ), a known paraspeckle component (Fox et al. 2002), fused to EYFP. To minimize cell-to-cell variation, clonal selection was performed to isolate a single cell line, designated C2C12 EYFP-PSPC1, for use in this study. By immunoblotting, we confirmed that endogenous PSPC1 is expressed in both wiletype (wt) C2C12 and C2C12 EYFP-PSPC1 cells (Fig. 4A, lanes $1,2)$, whereas the EYFP-PSPC1 fusion protein is detected only in the C2C12 EYFP-PSPC1 cell line (Fig. 4A, lanes 2,6). The level of endogenous PSPC1 is reduced in C2C12 EYFP-PSPC1 cells as compared to wt $\mathrm{C} 2 \mathrm{C} 12$ cells (Fig. 4A, lanes 1,2), indicating a potential cellular response to control the total level of PSPC1. To confirm that the C2C12 EYFP-PSPC1 cells allow accurate visualization of paraspeckles, a plasmid expressing mCherry fused to NONO (also known as p54/nrb), another known paraspeckle component (Fox et al. 2005), was transfected into C2C12 EYFP-PSPC1 cells. As expected, EYFP-PSPC1 and mCherryNONO colocalize in paraspeckles (Fig. 4B).

Using the C2C12 EYFP-PSPC1 cells, we found that RNA FISH probes to Men $\varepsilon / \beta$ colocalize with EYFP-PSPC1, indicating that the Men $\varepsilon / \beta$ ncRNAs are, indeed, localized to nuclear paraspeckles (Fig. 4C). Since A-to-I hyper-editing within inverted repeats of the 3'UTR of CTN-RNA was shown to act as a nuclear retention signal (Prasanth et al. 2005), we examined Men $\varepsilon$ transcripts for evidence of inverted repeats and/or hyper-editing. In contrast to CTN-RNA, the Men $\varepsilon$ transcripts lack any repeats, while the long Men $\beta$ ncRNA contains many repetitive elements. Upon searching for evidence of A-to-I hyper-editing in a mouse EST database, a single 106-nt region near the 3 '-end of Men $\varepsilon$ contained within EST clone
AA709912 exhibited a significant level of hyper-editing (11 out of 24 As were sequenced as a $\mathrm{G}$, indicative of A-to-I editing). However, subsequent cDNA cloning from $\mathrm{C} 2 \mathrm{C} 12$ cells failed to identify any additional evidence that the Men $\varepsilon / \beta$ transcripts are A-to-I hyper-edited (data not shown).

Next, we investigated whether the Men $\varepsilon / \beta$ transcripts interact with NONO. A mouse monoclonal antibody to NONO, designated 9-99, was generated (Fig. 4D) and used for coimmunoprecipitation (Co-IP) experiments using C2C12 cells. Two other bona fide components of paraspeckles, SFPQ (also known as Psf) and PSPC1, were coprecipitated along with NONO (Fig. 4E), as has been reported previously (Fox et al. 2005; Kuwahara et al. 2006). The IP fraction was next analyzed by RT-PCR for the presence of Men $\varepsilon / \beta$. Men $\varepsilon / \beta$ efficiently coimmunoprecipitated with NONO in C2C12 cells (Fig. 4E) and in NIH3T3 cells (data not shown). Collectively, our results demonstrate that both Men $\varepsilon / \beta$ transcripts localize to paraspeckles and associate with NONO.

\section{MEN $\varepsilon / \beta$ ncRNAs are essential components of nuclear paraspeckles}

It has previously been shown that RNase A treatment disrupts the integrity of nuclear paraspeckles (Fox et al. 2005; Prasanth et al. 2005), suggesting that one or more RNA species might serve a role in the structure and/or organization of these nuclear bodies. Thus far, the only other known RNA present in paraspeckles is $C T N-R N A$; however, knockdown of CTN-RNA by antisense oligonucleotides (ASOs) did not have any effect on the integrity of paraspeckles (Prasanth et al. 2005). To address whether the MEN $\varepsilon / \beta$ transcripts are essential for the structural integrity of nuclear paraspeckles, we depleted the level of MEN $\varepsilon / \beta$ using ASOs in HeLa cells stably expressing EYFP-PSPC1.

Three ASOs (ASO 1, 2, and 3) were targeted near the 3 '-end of the $M E N \varepsilon$ transcript such that they knock down both the MEN $\varepsilon$ and MEN $\beta$ transcripts (Fig. 5A). Similarly, one ASO (ASO 4) was targeted near the 3 '-end of the MEN $\beta$ transcript such that it knocks down only the MEN $\beta$ isoform (Fig. 5A). When these ASOs were independently transfected into HeLa EYFP-PSPC1 cells, $\sim 70 \%$ knockdown of $M E N \varepsilon / \beta$ (ASO 1,2 , or 3 ) and $50 \%$ knockdown of MEN $\beta$ (ASO 4) were observed by Q-PCR analysis $24 \mathrm{~h}$ post-transfection (Fig. 5B). The knockdown of MEN $\varepsilon$ and/or $\beta$ transcripts by the complementary ASOs and not by a control ASO was confirmed by RNA FISH (Fig. 5C). Interestingly, paraspeckles were disrupted in $\sim 80 \%$ of cells transfected with ASOs 1,2 , or 3 to the MEN $\varepsilon / \beta$ transcripts as visualized by the loss of EYFP-PSPC1 foci, while the control ASO had no effect on the integrity of paraspeckles (Fig. 5C,D). Knockdown of the MEN $\beta$ transcript specifically by ASO 4 also caused the disruption of paraspeckles, although to a lesser extent (Fig. 5C,D). A similar result was observed when wt HeLa cells were treated independently with ASOs 1-4 and paraspeckles were examined by immunofluorescence using the 9-99 monoclonal antibody that reacts with both PSPC1 and NONO from HeLa lysate (Supplemental Fig. 6). A small population of cells transfected with ASO 4 exhibited paraspeckles that were colocalized only with $M E N \varepsilon$ transcripts, but not with $M E N \beta$ transcripts, demonstrating that $M E N \varepsilon$ transcripts unambiguously localize to paraspeckles and are sufficient for paraspeckle integrity (Supplemental Fig. 6B). These results show that both MEN $\varepsilon / \beta$ transcripts are essential for the maintenance of nuclear paraspeckles.

One possible explanation for the observed disruption of paraspeckles is that the loss of the $M E N \varepsilon / \beta$ transcripts causes 
the degradation of EYFP-PSPC1. To clarify whether the level of EYFP-PSPC1 proteins was changed after knockdown of the MEN $\varepsilon / \beta$ transcripts, we performed immunoblotting using an anti-PSPC1 antibody. While the level of $M E N \varepsilon / \beta$ transcripts was reduced by transfection of the ASOs, PSPC1 remained relatively stable upon ASO treatment (Fig. 5E), providing further support that MEN $\varepsilon / \beta$ are involved in the structural organization of nuclear paraspeckles.

A

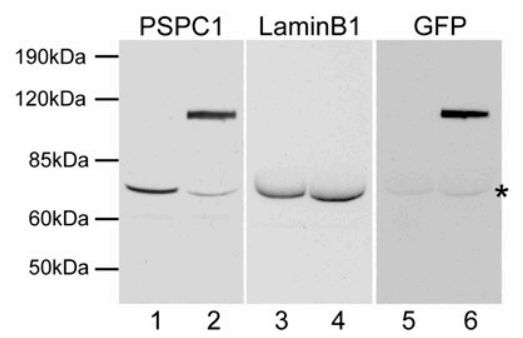

C
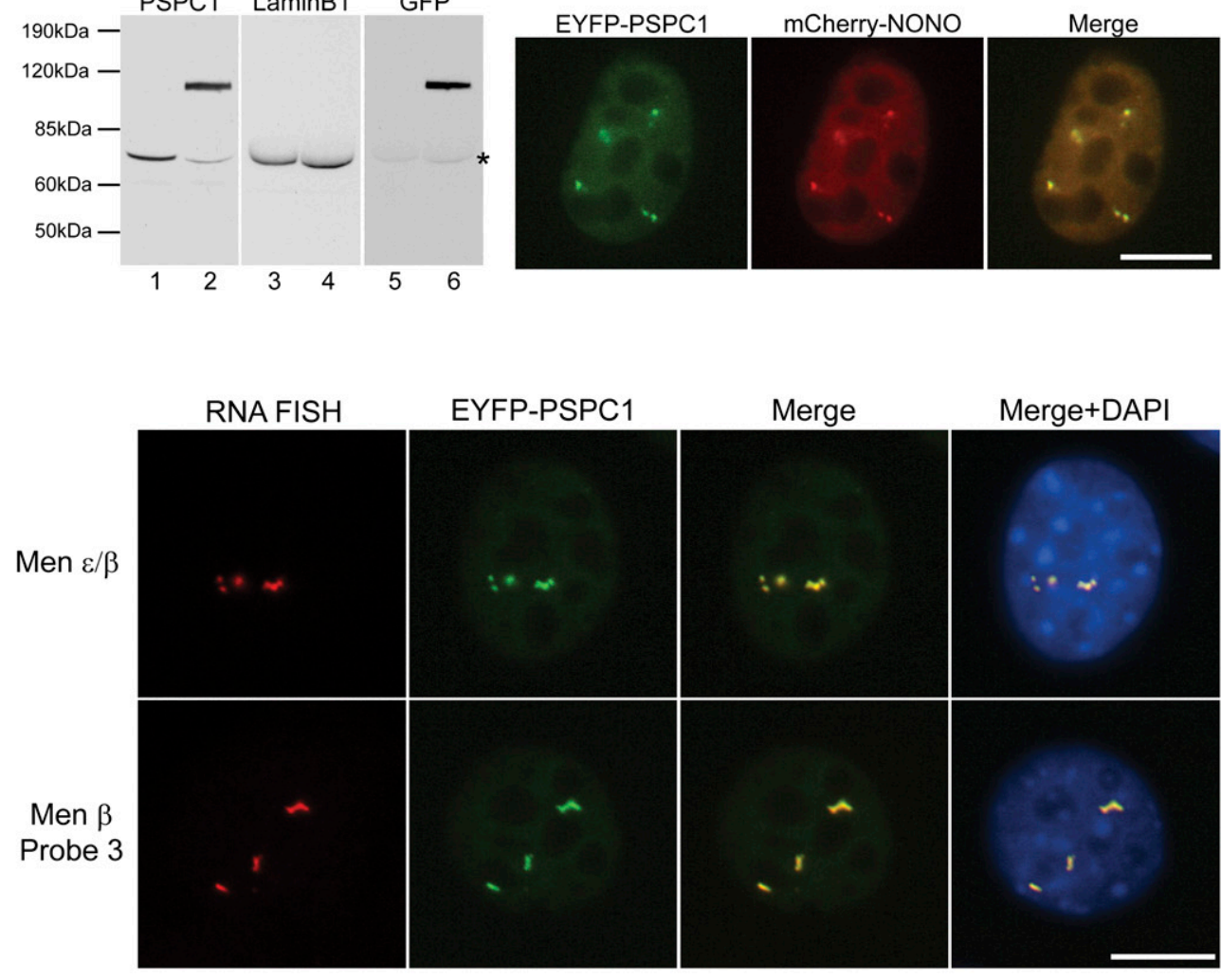

D

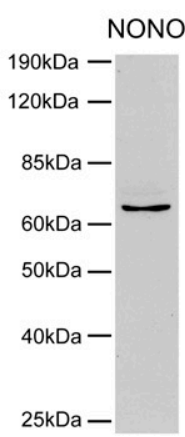

E
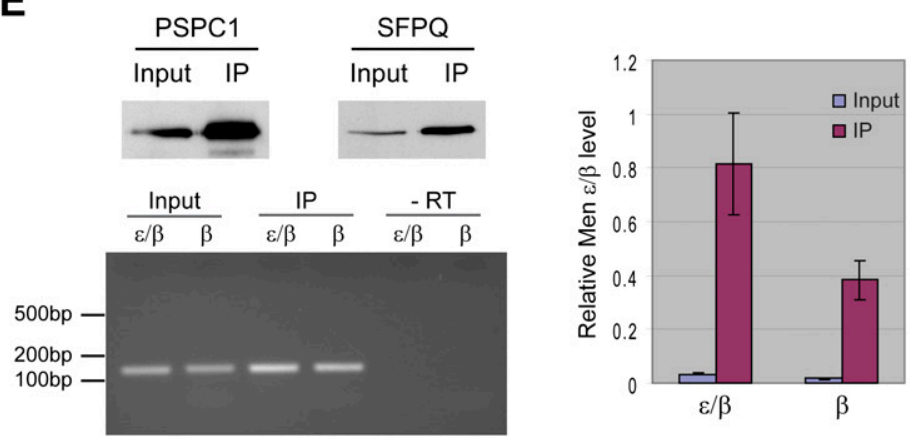

Figure 4. Men $\varepsilon / \beta$ transcripts are localized to nuclear paraspeckles. (A) A C2C12 cell line stably expressing EYFP fused to PSPC1 (also known as PSP1 $\alpha$ ) was established. Immunoblotting showed that the endogenous PSPC1 level was reduced in (lane 2, lower band) C2C12 EYFP-PSPC1 stable cells compared to in (lane 1) wt C2C12 cells. (Lanes 3,4) Lamin B1 served as a loading control in a duplicate blot. (Lanes 5,6) After stripping the anti-Lamin B1 antibody, immunoblotting using an anti-GFP antibody confirmed that the band at $\sim 100 \mathrm{kDa}$ corresponds to EYFP-PSPC1. (*) Residual Lamin B1 signal. (B) mCherry fused to NONO (also known as $\mathrm{p} 54 / \mathrm{nrb}$ ) was transiently expressed in C2C12 EYFP-PSPC1 stable cells. The foci of mCherry-NONO are colocalized with EYFP-PSPC1. Scale bar, $10 \mu \mathrm{m}$. (C) RNA FISH analysis showed that the Men $\varepsilon / \beta$ transcripts are localized to paraspeckles. A probe that detected both the Men $\varepsilon$ and Men $\beta$ transcripts, as well as a probe that only detects Men $\beta$, exhibit the same localization patterns. Scale bar, $10 \mu \mathrm{m}$. (D) A mouse monoclonal antibody to NONO, designated 9-99, was generated. Immunoblotting analysis using C2C12 whole-cell lysate detected a single band confirming the specificity of the $9-99$ monoclonal antibody. $(E)$ A coimmunoprecipitation assay revealed that the Men $\varepsilon / \beta$ transcripts directly interact with NONO. Immunoblotting using anti-PSPC1 or anti-SFPQ antibodies after co-IP showed that PSPC1 and SFPQ (also known as Psf) directly interact with NONO. Ten percent input was used for immunoblotting. CDNA was generated using random hexamers from the IP fraction. RT-PCR revealed the existence of the Men $\varepsilon / \beta$ transcripts in the NONO protein complex. Both Men $\varepsilon / \beta$ transcripts are $\sim 20$-fold enriched in the same IP fraction, assessed by Q-PCR. Gapdh was used as a normalization control in Q-PCR. The data in the histogram are shown as mean and standard deviation values of three technical replicates. 
A

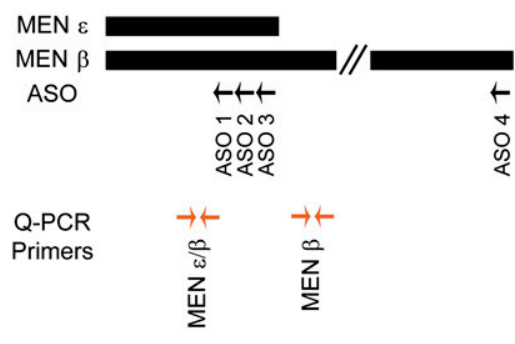

B

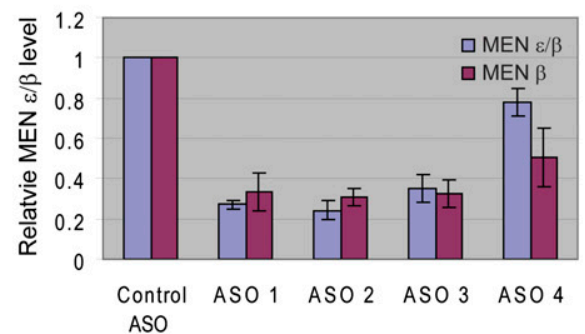

C

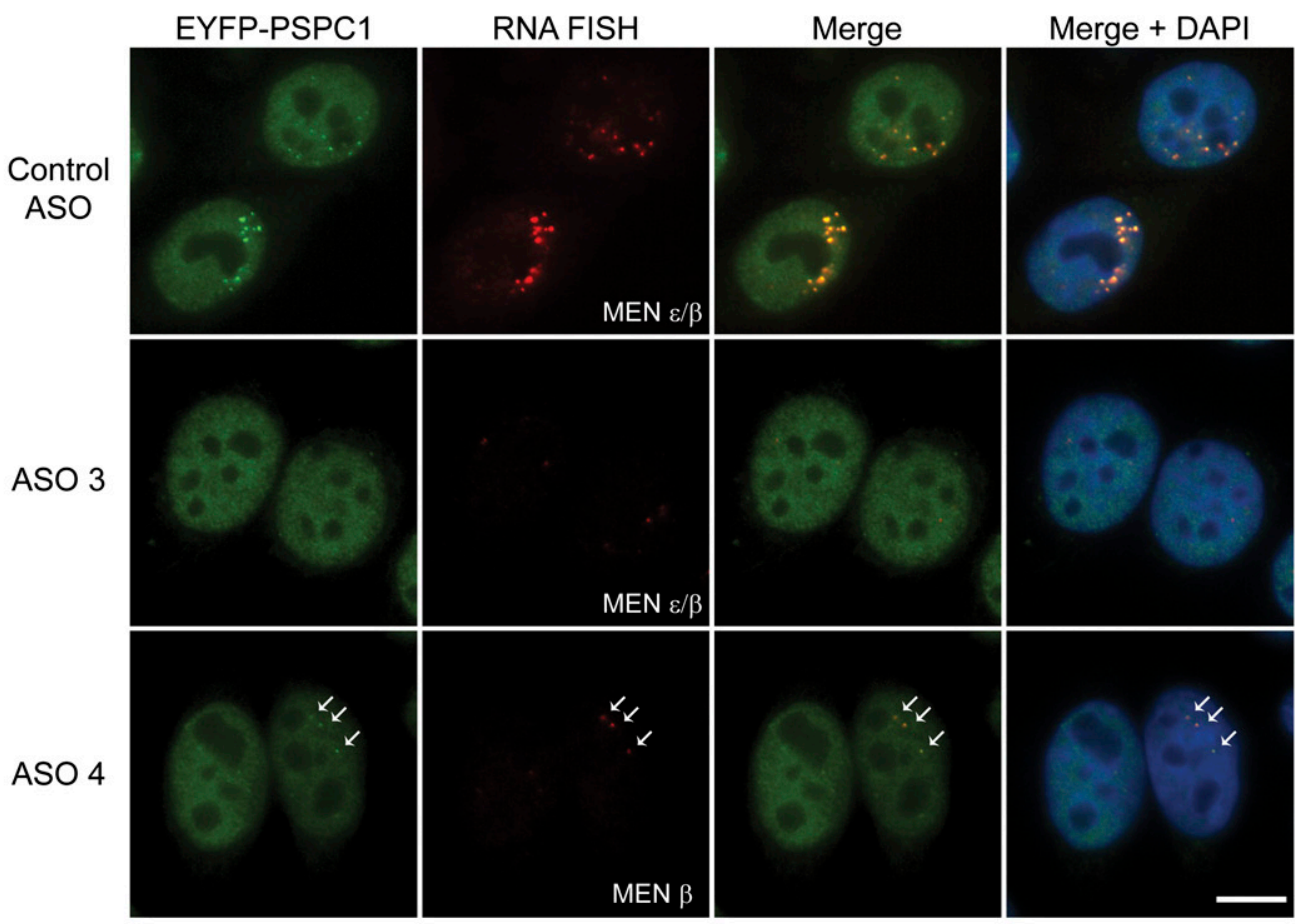

D

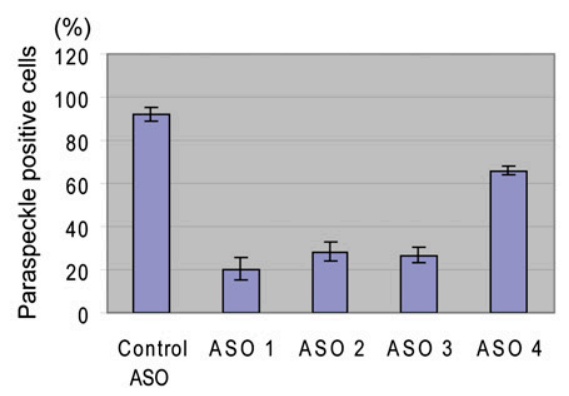

E

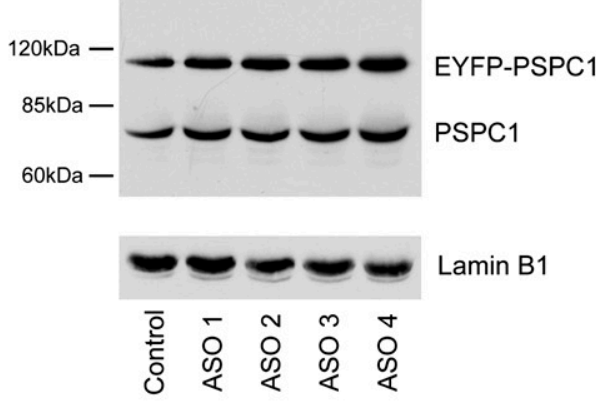

Figure 5. The $M E N \varepsilon / \beta$ transcripts are essential for the integrity of nuclear paraspeckles. $(A)$ Antisense oligonucleotides (ASO) were designed to knock down MEN $\varepsilon / \beta$ or MEN $\beta$ expression in HeLa cells. Three ASOs (ASO 1, 2, and 3) target both MEN $\varepsilon$ and $\beta$ isoforms, while ASO 4 targets only the MEN $\beta$ transcript. (Arrows) The positions where each ASO targets the MEN $\varepsilon / \beta$ transcripts. (B) Twenty-four hours after transfection of ASOs into HeLa cells stably expressing EYFP-PSPC1 (also known as PSP1 $\alpha$ ), an $\sim 70 \%$ knockdown of $M E N \varepsilon / \beta$ (ASO 1, 2, or 3 ) or $50 \%$ knockdown of $M E N \beta$ (ASO 4 ) was achieved, as assessed by Q-PCR. Beta-actin was used as a normalization control. The data in the histogram are shown as mean and standard deviation values of three independent experiments. (C) RNA FISH was performed $24 \mathrm{~h}$ after HeLa EYFP-PSPC1 cells were transfected with a control ASO or ASOs targeting the MEN $\varepsilon / \beta$ or $\beta$ transcript, to identify cells in which the RNAs were knocked down. In cells transfected with the control ASO, MEN $\varepsilon / \beta$ transcripts are localized to paraspeckles. Cells transfected with ASO 3 or 4 did not show paraspeckles. (Arrows) Residual paraspeckles in a cell where knockdown of the MEN $\beta$ transcript was not complete. Scale bar, $10 \mu \mathrm{m}$. (D) The portion of paraspeckle-positive cells was reduced to $\sim 20 \%$ by ASO 1 , 2, or 3, while control ASO did not appear to influence the integrity of paraspeckles. Treatment with ASO 4 resulted in a loss of paraspeckles, although to a lesser extent. The data in the histogram are shown as mean and standard deviation values of three independent experiments. Approximately 100 cells were counted per experiment. $(E)$ Knockdown of the MEN $\varepsilon / \beta$ transcripts did not result in degradation of the PSPC1 protein. Lamin B1 serves as a loading control. 
$M E N \varepsilon / \beta$ transcripts are required for the de novo formation of paraspeckles

It was previously shown that upon RNA polymerase II inhibition, paraspeckles are re-localized to the periphery of nucleoli forming nucleolar caps (Fox et al. 2002). After HeLa cells were treated with 5,6-dichlorobenzimidazole 1- $\beta$-D-ribofuranoside (DRB) for $1 \mathrm{~h}$, EYFP-PSPC1, indeed, formed nucleolar caps (Fig. 6A; Supplemental Fig. 7A). To be certain that DRB treatment did not affect the phosphorylation state of PSPC1, its migration rate on SDS-PAGE was examined \pm alkaline phosphatase treatment. Alkaline phosphatase treatment caused a band shift (Supplemental Fig. 7B, lanes $2,3)$, suggesting that PSPC1 is phosphorylated. However, DRB treatment did not affect the phosphorylation state of PSPC1 (Supplemental Fig. 7B). Upon DRB treatment, the MEN $\varepsilon / \beta$ transcripts failed to remain colocalized with EYFP-PSPC1 (Fig. 6A). MEN $\beta$ transcripts now exhibited a diffuse nuclear localization, while $M E N \&$ transcripts became concentrated only at nuclear speckles (Fig. 6A; Supplemental Fig. 7C). Since the half-life of MEN $\varepsilon / \beta$ is $\sim 4$ and $8 \mathrm{~h}$ (data not shown), respectively, the observed change in RNA localization resulted from redistribution rather than degradation. These data suggest that active transcription is required for $M E N \varepsilon / \beta$ localization to paraspeckles. Upon release from RNA polymerase II inhibition, paraspeckles were reformed within $2 \mathrm{~h}$ and contained the $M E N \varepsilon / \beta$ transcripts (Fig. 6A).

To next address whether the $M E N \varepsilon / \beta$ transcripts are essential for the initial formation of paraspeckles, we depleted $M E N \varepsilon / \beta$ expression in HeLa cells by ASO transfection followed by DRB treatment and release (Fig. 6B). When the level of $M E N \varepsilon / \beta$ or $M E N$ $\beta$ transcripts was assessed by Q-PCR $6 \mathrm{~h}$ after ASO transfection, $40 \%-80 \%$ knockdown of MEN $\varepsilon$ and/or $\beta$ expression was achieved by ASOs 1-4 (Fig. 6C). The depletion of both $M E N \varepsilon / \beta$ transcripts (by ASO 1, 2, and 3) or MEN $\beta$ transcripts alone (by ASO 4) resulted in suppression of paraspeckle reformation after release from DRB treatment (Fig. 6B,D), suggesting that the $M E N \varepsilon / \beta$ transcripts are required for the reformation of paraspeckles. ASO 4, which exclusively targets MEN $\beta$ transcripts, suppressed the reformation of nuclear paraspeckles, but to a lesser degree (Fig. 6B,D). Our data suggest that both the $M E N \varepsilon / \beta$ transcripts are required for the initial formation of paraspeckles.

\section{Discussion}

In the present study, we have identified 184 ncRNAs that are up- or down-regulated more than twofold upon $\mathrm{C} 2 \mathrm{C} 12$ myoblast differentiation into myotubes. We have focused on the Men $\varepsilon / \beta$ locus, which yields two long ncRNAs localizing to nuclear paraspeckles. Men $\varepsilon$ and Men $\beta$ ncRNAs are transcribed from the same RNA polymerase II promoter but differ in the location of their $3^{\prime}$ ends. While the Men $\varepsilon$ transcript is polyadenylated, the 3 '-end of the Men $\beta$ transcript is generated by RNase $\mathrm{P}$ cleavage after a short genomically encoded poly(A)-rich tract. Depletion of the $M E N \varepsilon / \beta$ transcripts from cells resulted in the disruption of paraspeckles. Our data demonstrate that the $M E N \varepsilon / \beta$ transcripts are essential for establishing paraspeckles de novo as well as for maintaining the structural integrity of paraspeckles in cell nuclei.

\section{MEN $\varepsilon / \beta$ ncRNAs as a structural platform of paraspeckles}

Mammalian nuclei are highly compartmentalized organelles harboring numerous nuclear domains including, but not limited to, nucleoli, speckles, PML bodies, Cajal bodies, and paraspeckles (for review, see Spector 2001, 2006). The molecular components responsible for organizing and maintaining the structural integrity of nuclear domains are largely unknown except that the promyelocytic leukemia (PML) protein is required for the maintenance of PML bodies (Dyck et al. 1994). The idea that RNA may serve a structural and/or organizational role in the cell nucleus surfaced early on in biochemical and cell biological studies (Smetana et al. 1963; Berezney and Coffey 1974; Perry et al. 1974; Brawerman and Diez 1975; Herman et al. 1976; Fey et al. 1986). Interestingly, paraspeckles were previously shown to be sensitive to RNase A treatment (Fox et al. 2005; Prasanth et al. 2005). Here we show that the $M E N \varepsilon / \beta$ ncRNAs are essential for the structural integrity of paraspeckles in cell nuclei (Figs. 5, 6). Several paraspeckle proteins including PSPC1, SFPQ, and NONO contain two RNA recognition motifs. We demonstrate that the Men $\varepsilon / \beta$ transcripts are in the same complex as NONO, PSPC1, and SFPQ, suggesting that this RNP complex is likely involved in establishing paraspeckles. Upon transcriptional inhibition, PSPC1 and SFPQ relocalize to the periphery of nucleoli (Fox et al. 2002, 2005). Surprisingly, the MEN $\varepsilon / \beta$ transcripts do not follow PSPC1 and SFPQ to the nucleolar cap, but instead localize to speckles as well as being diffusely distributed within the nucleoplasm, respectively (Fig. 6). Further studies are required to elucidate the signals received by paraspeckles allowing them to respond to the transcriptional activity of the cell and alter their nuclear organization.

Although paraspeckles were identified several years ago, their function still remains elusive (Fox et al. 2002). Prasanth et al. (2005) showed that paraspeckles serve as a storage depot for a specific nuclear-retained RNA, CTN-RNA. However, knockdown of $C T N-R N A$ did not result in an alteration of paraspeckles (Prasanth et al. 2005). Our report demonstrates that the structural integrity of paraspeckles depends on the existence of RNA, namely, the $M E N \varepsilon / \beta$ transcripts. However, we cannot rule out the possibility that additional RNAs/RNPs may also play a role in the organization of this nuclear compartment. Further characterization of the $M E N \varepsilon / \beta$ ncRNAs will provide additional insights into the structure and function of paraspeckles.

\section{Dynamic regulation of ncRNAs during muscle differentiation}

Studies of mammalian transcriptomes have suggested that ncRNAs constitute a significant portion of the output of their genomes (Carninci et al. 2005; Kapranov et al. 2007). Recently, the regulation of long ncRNAs has been studied in various developmental processes including bovine muscle development (Lehnert et al. 2007) and ES cell differentiation (Dinger et al. 2008). We have found large-scale changes in the regulation of ncRNAs upon C2C12 muscle cell differentiation (Supplemental Table 1), supporting the premise that ncRNAs are likely important players, in terms of genomic output, rather than transcriptional noise or non-functional RNAs. Since we only examined a small subset of the known ncRNAs, there are presumably many more that also exhibit dynamic expression change in muscle differentiation and other developmental contexts. The biological functions of these ncRNAs in muscle differentiation and cell biology remain to be investigated.

In this study, we have focused on the Men $\varepsilon / \beta$ locus, which yields two ncRNAs that localize to paraspeckles (Fig. 4). Men $\varepsilon / \beta$ transcripts are 3.3-fold up-regulated during myoblast differentiation (Fig. 1; Supplemental Table 1). Recently, the bovine ortholog of the Men $\varepsilon$ transcript was shown to be 6.8 -fold up-regulated during the late stages of muscle development (Lehnert et al. 2007). 
However, Lehnert et al. (2007) argued that this observed up-regulation was due to the existence of multiple nuclei per myotube causing nuclear-retained RNAs to be a larger portion of the total
RNA present in the myotubes rather than due to increased transcriptional output of the Men $\varepsilon / \beta$ locus. Our results indicate that the nuclear foci of Men $\varepsilon / \beta$ ncRNAs were enlarged in myotube

A

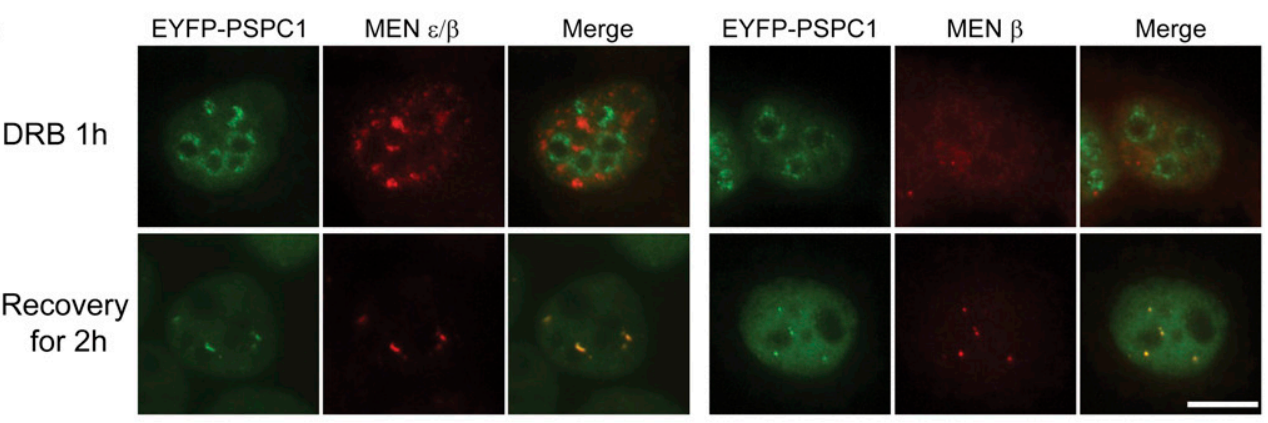

B

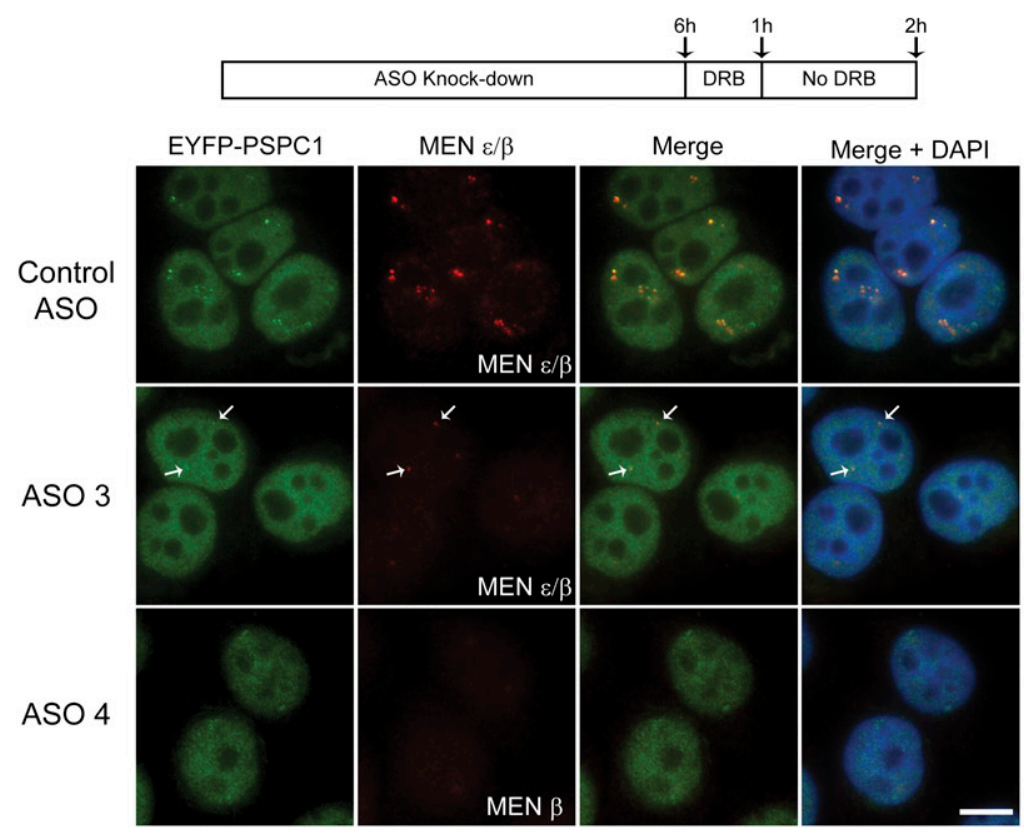

C

D
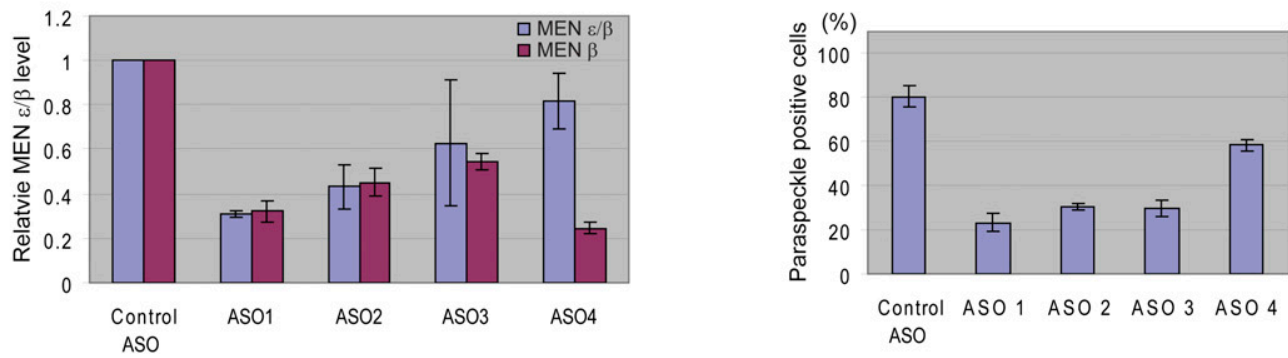

Figure 6. The reformation of paraspeckles after release from transcriptional inhibition is suppressed in $M E N \varepsilon / \beta$-depleted cells. ( $A$ ) Upon DRB treatment for $1 \mathrm{~h}$, EYFP-PSPC1 (also known as PSP1 $\alpha$ ) relocalized to the periphery of nucleoli. The MEN $\beta$ transcript lost paraspeckle localization, while the MEN $\varepsilon$ transcript relocalized to speckles. Upon removal of DRB and recovery for $2 \mathrm{~h}$, paraspeckles reformed and colocalized with the $M E N \varepsilon / \beta$ transcripts. (B) Cells were treated with ASOs to knock down MEN $\varepsilon / \beta$ expression prior to DRB treatment and recovery. In cells treated with a control ASO, paraspeckles reformed within $2 \mathrm{~h}$ of recovery. In contrast, paraspeckles did not re-form when MEN $\varepsilon / \beta$ (ASO 3) or MEN $\beta$ alone (ASO 4) was depleted. (Arrows) Residual paraspeckles in a cell where knockdown of the $M E N \varepsilon / \beta$ transcripts was not complete. Scale bar, $10 \mu \mathrm{m}$. (C) Q-PCR was used to assess the ASO knockdown efficiency after $6 \mathrm{~h}$ of ASO treatment. A 40\%-70\% knockdown of MEN $\varepsilon / \beta$ (ASO 1, 2, or 3) or $\sim 75 \%$ knockdown of MEN $\beta$ (ASO 4) was achieved. Betaactin was used as a normalization control. The data in the histogram are shown as mean and standard deviation values of three independent experiments. (D) The percentage of paraspeckle positive cells was reduced to $20 \%-30 \%$ by ASO 1 , 2, or 3 , while the control ASO did not influence the integrity of paraspeckles. Treatment with ASO 4 also resulted in a loss of paraspeckles, although to a lesser extent. The data in the histogram are shown as mean and standard deviation values of three independent experiments. Approximately 100 cells were counted per experiment. 
nuclei compared to myoblast nuclei (Fig. 1), suggesting that Men $\varepsilon /$ $\beta$ transcripts are, in fact, present at a higher level in myotubes. In addition to muscle differentiation-related regulation, Men $\varepsilon$ transcripts have been reported to be up-regulated in mouse brain infected with Japanese encephalitis virus or Rabies virus (Saha et al. 2006), although the biological significance of this induced expression remains to be explored.

The MEN $\varepsilon / \beta$ locus has previously been reported to produce a $0.5-\mathrm{kb}$ ncRNA in human trophoblast that mapped to the $3^{\prime}$ end of the MEN $\varepsilon$ transcript. This RNA was called trophoblast STAT utron (TSU) or trophoblast ncRNA (TncRNA) (Peyman 1999; Geirsson et al. 2003a,b). In one case, it was suggested that TSU binds to STAT1 in the cytoplasm to repress nuclear import of the STAT1 protein (Peyman 1999). In another case, TncRNA was reported to suppress class II and III transactivator promoters resulting in the absence of major histocompatibility antigens (MHC) in trophoblast (Geirsson et al. 2003a,b). However, we were unable to detect this $0.5-\mathrm{kb}$ RNA using human or mouse total placenta RNA (data not shown). Furthermore, the MEN $\varepsilon / \beta$ transcripts are exclusively retained in the nucleus (Hutchinson et al. 2007).

\section{Processing of the Men $\varepsilon / \beta$ ncRNAs}

The $3^{\prime}$ end of the Men $\beta$ transcript is generated by RNase P cleavage, rather than by the classical cleavage/polyadenylation machinery. The 3' end of another ncRNA, Malat1, was recently shown to be generated by the tRNA processing machinery (Wilusz et al. 2008). Curiously, the MALAT1/Malat1 locus is located immediately adjacent to the MEN $\beta / \mathrm{Men} \beta$ locus, $55 \mathrm{~kb}$ or $23 \mathrm{~kb}$ downstream from the $3^{\prime}$ end of MEN $\beta / \mathrm{Men} \beta$ in the human and mouse genomes, respectively. tRNA-like structures are located immediately downstream from a genomically encoded poly(A)rich tract at the 3 ' ends of both the Men $\beta$ and Malat1 nascent transcripts. The tRNA-like structures are recognized by RNase $P$, which cleaves to generate the $3^{\prime}$-end of the mature Men $\beta$ and Malat1 transcripts. The Malat1 tRNA-like structure is further processed by RNase $Z$ and the CCA-adding enzyme, resulting in a 61-nt tRNA-like mascRNA that is subsequently exported to the cytoplasm (Wilusz et al. 2008). Somewhat surprisingly, a small tRNA-like transcript originating from the $M E N \beta /$ Men $\beta$ locus failed to accumulate to a significant steady-state level in many examined tissues/cell lines, probably because it is rapidly degraded. The mascRNA half-life is only $\sim \mathrm{h}$ (Wilusz et al. 2008), suggesting that the tRNA-like transcript may be inherently unstable. Consistent with this notion, recent studies have revealed a large class of RNAs that are rapidly degraded by the exosome, but can be stabilized by mutations in exosome components (Wyers et al. 2005; Davis and Ares 2006). Besides Men $\beta$ transcripts and Malat1, it is not known how many other RNA polymerase II transcripts are subject to 3 'end cleavage by RNase P.

In addition to being processed by a similar 3 '-end processing mechanism, both Men $\beta$ and Malat1 are stable nuclear-retained RNAs. Men $\beta$ localizes to paraspeckles, while Malat1 localizes to speckles (Fig. 4; Hutchinson et al. 2007). A-to-I hyper-editing has been suggested as one mechanism for RNA nuclear retention (Kumar and Carmichael 1997; Zhang and Carmichael 2001; Prasanth et al. 2005; Chen et al. 2008). Interestingly, one paraspeckle protein, NONO, was previously shown to be responsible for nuclear retention of hyper-edited RNAs (Zhang and Carmichael 2001). Of the known large nuclear-retained RNAs, CTN-RNA was shown to bind to NONO and PSPC1 and its 3'-UTR was subject to A-to-I hyper-editing (Prasanth et al. 2005). More recently,
NONO was shown to be colocalized with nuclear-retained RNAs harboring hyper-edited inverted Alu repeats (Chen et al. 2008). Although the Men $\varepsilon / \beta$ transcripts are a part of the NONO complex, we were unable to detect any editing of the Men $\varepsilon / \beta$ transcripts in C2C12 cells. In addition, Men $\varepsilon$ and Malat1 do not appear to contain any inverted repeats, suggesting that there are likely additional mechanisms for nuclear retention of RNA. Further characterization of the Men $\varepsilon / \beta$ transcripts will determine whether any sequence motifs or secondary structures serve as nuclear retention or paraspeckle localization signals.

In summary, we have identified two ncRNAs that localize to paraspeckles and are responsible for establishing and maintaining these nuclear structures. Our data provide the first demonstration that ncRNAs play a critical role in nuclear organization. Future studies will focus on additional roles of ncRNAs in nuclear structure/function.

\section{Methods}

\section{Cell culture and drug treatments}

$\mathrm{C} 2 \mathrm{C} 12$ and HeLa cells were grown at $37^{\circ} \mathrm{C}, 5 \% \mathrm{CO}_{2}$ in DMEM supplemented with $10 \%$ fetal bovine serum (FBS) and penicillinstreptomycin. Differentiation of C2C12 myoblast cells into myotubes was induced by incubation in DMEM supplemented with $10 \%$ horse serum for $5 \mathrm{~d}$. RNA polymerase II was inhibited by DRB $\left(33 \mu \mathrm{g} / \mathrm{mL}\right.$; Sigma) for $1 \mathrm{~h}$ at $37^{\circ} \mathrm{C}$.

\section{Microarray analysis}

Total RNA from $\mathrm{C} 2 \mathrm{C} 12$ cells that had been induced to form myotubes for $0 \mathrm{~h}, 24 \mathrm{~h}$, or $5 \mathrm{~d}$ was isolated and treated with DNase I (Invitrogen). RNA was then amplified and labeled using the Amino Allyl Message Amp II kit (Ambion) and hybridized to a previously described custom non-coding RNA microarray (Dinger et al. 2008). The custom microarray design and microarray expression from this study have been submitted to ArrayExpress under Accession ID E-TABM-575.

\section{RNA isolation and Northern blotting}

TRIzol was used for all total RNA isolations as per the manufacturer's instructions (Invitrogen). Ten micrograms of total RNA from mouse tissues was separated by electrophoresis through a $1 \%$ denaturing agarose gel and transferred to Hybond-N membrane (GE Healthcare) by capillary transfer. Pre-hybridization and hybridization were carried out in NorthernMax Prehyb/Hyb Buffer (Ambion) at $42^{\circ} \mathrm{C}$. Labeling of random-labeled probes was performed using the Prime-It RmT Random Primer Labeling Kit (Stratagene). Oligo probes were labeled with $\left[\gamma^{3}{ }^{32} \mathrm{P}\right]$ ATP using T4 polynucleotide kinase (New England Biolabs). Blots were visualized and quantified using the Fujifilm Life Science FLA-5100 imaging system.

To map the 3' end of $M E N \beta, 15 \mu \mathrm{g}$ of HeLa total RNA was first mixed with $20 \mathrm{pmol}$ of antisense oligo and heated for $10 \mathrm{~min}$ to $65^{\circ} \mathrm{C}$. After allowing the antisense oligo to anneal by slow cooling, the RNA was treated with RNase $\mathrm{H}$ (New England Biolabs) for $30 \mathrm{~min}$ at $37^{\circ} \mathrm{C}$ and then subjected to small RNA Northern blot analysis, as previously described (Wilusz et al. 2008). Primer and probe sequences are included in the Supplemental Methods.

\section{RNase protection assay (RPA)}

Mouse beta-actin and Men $\beta$ probes were internally labeled using $\left[\alpha-{ }^{32}\right.$ P]UTP and gel-purified. The RPA III kit (Ambion) was used as 
per the manufacturer's instructions. Beta-actin and Men $\beta$ probes at $2000 \mathrm{cpm}$ and $16,000 \mathrm{cpm}$, respectively, were allowed to hybridize to $10 \mu \mathrm{g}$ of total RNA from mouse tissues and C2C12 cells. After unprotected nucleotides were digested by RNase T1 for 30 min at $37^{\circ} \mathrm{C}$, samples were electrophoresed on $4 \%$ polyacrylamide/8 $\mathrm{M}$ urea gels.

\section{In vitro cleavage assays}

Mouse Men $\beta$ RNA substrates were internally labeled using $[\alpha-$ $\left.{ }^{32} \mathrm{P}\right]$ UTP, gel-purified, and used at $10,000 \mathrm{cpm}$ per cleavage reaction. Partially purified HeLa RNase $\mathrm{P}$ was generously provided by Sidney Altman (Yale University). RNase P reactions were incubated for $1 \mathrm{~h}$ at $37^{\circ} \mathrm{C}$ in $50 \mathrm{mM}$ Tris- $\mathrm{HCl}$ (pH 7.5), $10 \mathrm{mM} \mathrm{MgCl}_{2}$, and 100 $\mathrm{mM} \mathrm{NH}{ }_{4} \mathrm{Cl}$. Recombinanat His-tagged tRNase ZL (delta30) was generously provided by Masayuki Nashimoto (Niigata University), and reactions were incubated for $30 \mathrm{~min}$ at $37^{\circ} \mathrm{C}$ in $10 \mathrm{mM}$ Tris$\mathrm{HCl}$ (pH 7.5), $1.5 \mathrm{mM}$ DTT, and $10 \mathrm{mM} \mathrm{MgCl}_{2}$. All reactions were stopped by adding gel loading dye, and samples were electrophoresed on $8 \%$ polyacrylamide/ $8 \mathrm{M}$ urea gels. The in vitro RNase $\mathrm{P}$ cleavage site was cloned using the GeneRacer kit (Invitrogen) according to the manufacturer's instructions, except that CIP and TAP treatments were omitted.

\section{RNA FISH/microscopy}

RNA FISH using nick-translated cDNA probes was performed as previously described (Prasanth et al. 2005). Cells were examined using an Axioplan 2i fluorescence microscope (Carl Zeiss) equipped with a $63 \times / 1.4$ N.A. objective lens and Chroma filters (Chroma Technology). OpenLab software (Improvision) was used to collect digital images from an ORCA cooled charge-coupled device camera (Hamamatsu).

\section{Establishment of EYFP-PSPCl stable cell lines}

EYFP-PSPC1 (Fox et al. 2002) was cloned into the pMSCV-Puro vector (Clontech), which was then transfected into Phoenix packaging cells. C2C12 or HeLa cells were infected by virus for $24 \mathrm{~h}$ and were selected under $1.3 \mu \mathrm{g} / \mathrm{mL}$ or $0.35 \mu \mathrm{g} / \mathrm{mL}$ puromycin, respectively, for $1 \mathrm{wk}$. FACS analysis was performed to isolate EYFPpositive cells, followed by clonal selection.

\section{Generation of 9-99 monoclonal antibody}

GST-PSPC1 was expressed in BL21(DE3) cells using the pGEX-6P system (GE Healthcare). PreScission Protease (GE Healthcare) was used to cleave the GST tag from PSPC1. PSPC1 protein was then injected into mice, hybridomas were established, and supernatants from 96 hybridomas were screened for specificity of antigen recognition by immunofluorescence microscopy and immunoblotting. One of the supernatants, 9-99, specifically recognized mouse NONO instead of PSPC1 because of amino acid homology between the two proteins, while it recognized both human PSPC1 and NONO.

\section{Q-PCR}

For real-time quantitative PCR (Q-PCR), $1 \mu \mathrm{g}$ of total RNA was treated with DNase I (Invitrogen) and reverse-transcribed to cDNA using TaqMan Reverse Transcription Reagents (Applied Biosystems). Gene-specific primer sets were designed using Primer 3 software. Q-PCR was carried out in triplicate using SYBR Green PCR Master Mix (Applied Biosystems), and beta-actin served as an endogenous normalization control.

\section{Knockdown of $M E N \varepsilon / \beta$ transcripts}

Second generation 2'-O-methoxyethyl oligonucleotides were synthesized at ISIS Pharmaceuticals to the target MEN $\varepsilon / \beta$ transcripts and tested for their efficacy. All antisense oligonucleotide sequences are included in the Supplemental Methods. Oligonucleotides were administered at a final concentration of $200 \mathrm{nM}$ to HeLa cells using Lipofectamine RNAiMAX (Invitrogen). Cells were incubated with a mixture of Lipofectamine RNAiMAX and oligonucleotide in Opti-MEM I medium (Invitrogen) at $37^{\circ} \mathrm{C}, 5 \% \mathrm{CO}_{2}$. After $6 \mathrm{~h}$, the transfection mixture was aspirated from the cells and replaced with fresh DMEM supplemented with 10\% FBS and incubated at $37^{\circ} \mathrm{C}, 5 \% \mathrm{CO}_{2}$ for an additional $16-18 \mathrm{~h}$ prior to assays.

\section{Coimmunoprecipitation}

C2C12 cell lysate was prepared in RIPA buffer containing AntiRNase (Ambion) and Complete Mini Protease Inhibitor (Roche Diagnostics). Following lysate centrifugation, the supernatant was incubated for $1 \mathrm{~h}$ at $4^{\circ} \mathrm{C}$ with antibody conjugated Dynabeads Protein A (Invitrogen). Beads were then washed four times in RIPA buffer. Eighty percent of the IP material was used for extraction of RNA using TRIzol (Invitrogen) and subsequent RT-PCR.

\section{Acknowledgments}

We thank Angus Lamond (University of Dundee), Yasuyuki Kurihara (Yokohama National University), Johannes Zuber (Lowe lab, CSHL), Sidney Altman (Yale University), and Masayuki Nashimoto (Niigata University) for PSPC1 antibody, SFPQ antibody, retroviral vectors, human RNase $P$, and human RNase $Z$, respectively. We thank Evgenij Glazov and George Muscat for providing the myoblast RNA samples for microarray analyses. We thank C. Frank Bennett, Sue Freier, and Chris Black at ISIS Pharmaceuticals for ASOs and helpful discussions. We thank Carmelita Bautista for developing monoclonal antibodies. We also thank Kannanganattu Prasanth, Zhenyu Xuan, Rajika Thakar, Megan Bodnar, and members of the Spector and Mattick laboratories for many helpful discussions. J.E.W. is supported by a Beckman Graduate studentship at the Watson School of Biological Sciences. J.S.M. is funded by the Australian Research Council (grant number FF0561986), and D.L.S. is funded by NIH/NIGMS 42694 and a grant from the Louis Morin Charitable Trust.

\section{References}

Berezney, R. and Coffey, D.S. 1974. Identification of a nuclear protein matrix. Biochem. Biophys. Res. Commun. 60: 1410-1417.

Birney, E., Stamatoyannopoulos, J.A., Dutta, A., Guigo, R., Gingeras, T.R., Margulies, E.H., Weng, Z., Snyder, M., Dermitzakis, E.T., Thurman, R.E. et al. 2007. Identification and analysis of functional elements in $1 \%$ of the human genome by the ENCODE pilot project. Nature 447: 799-816.

Brawerman, G. and Diez, J. 1975. Metabolism of the polyadenylate sequence of nuclear RNA and messenger RNA in mammalian cells. Cell 5: $271-280$.

Bussemakers, M.J., van Bokhoven, A., Verhaegh, G.W., Smit, F.P., Karthaus, H.F., Schalken, J.A., Debruyne, F.M., Ru, N., and Isaacs, W.B. 1999. DD3: a new prostate-specific gene, highly overexpressed in prostate cancer. Cancer Res. 59: 5975-5979.

Carninci, P., Kasukawa, T., Katayama, S., Gough, J., Frith, M.C., Maeda, N., Oyama, R., Ravasi, T., Lenhard, B., Wells, C., et al. 2005. The transcriptional landscape of the mammalian genome. Science 309: 1559-1563.

Chen, L.L., DeCerbo, J.N., and Carmichael, G.G. 2008. Alu elementmediated gene silencing. EMBO J. 27: 1694-1705.

Costa, F.F. 2005. Non-coding RNAs: New players in eukaryotic biology. Gene 357: $83-94$.

Davis, C.A. and Ares Jr., M. 2006. Accumulation of unstable promoterassociated transcripts upon loss of the nuclear exosome subunit Rrp6p in Saccharomyces cerevisiae. Proc. Natl. Acad. Sci. 103: 3262-3267.

\section{Genome Research}


Dinger, M.E., Amaral, P.P., Mercer, T.R., Pang, K.C., Bruce, S.J., Gardiner, B.B., Askarian-Amiri, M.E., Ru, K., Solda, G., Simons, C., et al. 2008. Long noncoding RNAs in mouse embryonic stem cell pluripotency and differentiation. Genome Res. 18: $1433-1445$.

Dyck, J.A., Maul, G.G., Miller Jr., W.H., Chen, J.D., Kakizuka, A., and Evans, R.M. 1994. A novel macromolecular structure is a target of the promyelocyte-retinoic acid receptor oncoprotein. Cell 76: $333-343$.

Erwin, J.A. and Lee, J.T. 2008. New twists in X-chromosome inactivation. Curr. Opin. Cell Biol. 20: 349-355.

Fey, E.G., Krochmalnic, G., and Penman, S. 1986. The nonchromatin substructures of the nucleus: The ribonucleoprotein (RNP)-containing and RNP-depleted matrices analyzed by sequential fractionation and resinless section electron microscopy. J. Cell Biol. 102: 1654-1665.

Fox, A.H., Lam, Y.W., Leung, A.K., Lyon, C.E., Andersen, J., Mann, M., and Lamond, A.I. 2002. Paraspeckles: A novel nuclear domain. Curr. Biol. 12: $13-25$.

Fox, A.H., Bond, C.S., and Lamond, A.I. 2005. P54nrb forms a heterodimer with PSP1 that localizes to paraspeckles in an RNA-dependent manner. Mol. Biol. Cell 16: 5304-5315.

Geirsson, A., Lynch, R.J., Paliwal, I., Bothwell, A.L., and Hammond, G.L. 2003a. Human trophoblast noncoding RNA suppresses CIITA promoter III activity in murine B-lymphocytes. Biochem. Biophys. Res. Commun. 301: $718-724$

Geirsson, A., Paliwal, I., Lynch, R.J., Bothwell, A.L., and Hammond, G.L. 2003b. Class II transactivator promoter activity is suppressed through regulation by a trophoblast noncoding RNA. Transplantation 76: 387394.

Guru, S.C., Agarwal, S.K., Manickam, P., Olufemi, S.E., Crabtree, J.S., Weisemann, J.M., Kester, M.B., Kim, Y.S., Wang, Y., Emmert-Buck, M.R. et al. 1997. A transcript map for the $2.8-\mathrm{Mb}$ region containing the multiple endocrine neoplasia type 1 locus. Genome Res. 7: 725-735.

Heard, E. and Disteche, C.M. 2006. Dosage compensation in mammals: Fine-tuning the expression of the X chromosome. Genes \& Dev. 20: 1848-1867.

Herman, R.C., Williams, J.G., and Penman, S. 1976. Message and nonmessage sequences adjacent to poly(A) in steady state heterogeneous nuclear RNA of HeLa cells. Cell 7: 429-437.

Hirota, K., Miyoshi, T., Kugou, K., Hoffman, C.S., Shibata, T., and Ohta, K. 2008. Stepwise chromatin remodelling by a cascade of transcription initiation of non-coding RNAs. Nature 456: 130-134.

Hutchinson, J.N., Ensminger, A.W., Clemson, C.M., Lynch, C.R., Lawrence, J.B., and Chess, A. 2007. A screen for nuclear transcripts identifies two linked noncoding RNAs associated with SC35 splicing domains. BMC Genomics 8: 39. doi: 10.1186/1471-2164-8-39.

International Human Genome Sequencing Consortium. 2004. Finishing the euchromatic sequence of the human genome. Nature 431: 931-945.

Ji, P., Diederichs, S., Wang, W., Boing, S., Metzger, R., Schneider, P.M., Tidow, N., Brandt, B., Buerger, H., Bulk, E., et al. 2003. MALAT-1, a novel noncoding RNA, and thymosin beta4 predict metastasis and survival in early-stage non-small cell lung cancer. Oncogene 22: 8031-8041.

Kapranov, P., Cheng, J., Dike, S., Nix, D.A., Duttagupta, R., Willingham, A.T., Stadler, P.F., Hertel, J., Hackermuller, J., Hofacker, I.L., et al. 2007. RNA maps reveal new RNA classes and a possible function for pervasive transcription. Science 316: 1484-1488.

Kumar, M. and Carmichael, G.G. 1997. Nuclear antisense RNA induces extensive adenosine modifications and nuclear retention of target transcripts. Proc. Natl. Acad. Sci. 94: 3542-3547.

Kuwahara, S., Ikei, A., Taguchi, Y., Tabuchi, Y., Fujimoto, N., Obinata, M., Uesugi, S., and Kurihara, Y. 2006. PSPC1, NONO, and SFPQ are expressed in mouse Sertoli cells and may function as coregulators of androgen receptor-mediated transcription. Biol. Reprod. $\mathbf{7 5}$ : 352-359.

Lehnert, S., Reverter, A., Byrne, K., Wang, Y., Nattrass, G., Hudson, N., and Greenwood, P. 2007. Gene expression studies of developing bovine longissimus muscle from two different beef cattle breeds. BMC Dev. Biol. 7: 95. doi: 10.1186/1471-213X-7-95.
Lin, R., Maeda, S., Liu, C., Karin, M., and Edgington, T.S. 2007. A large noncoding RNA is a marker for murine hepatocellular carcinomas and a spectrum of human carcinomas. Oncogene 26: 851-858.

Mattick, J.S. 2004. RNA regulation: A new genetics? Nat. Rev. Genet. 5: 316 323.

Mattick, J.S. and Makunin, I.V. 2006. Non-coding RNA. Hum Mol Genet 15 (Spec No 1): R17-R29.

Mercer, T.R., Dinger, M.E., Sunkin, S.M., Mehler, M.F., and Mattick, J.S. 2008. Specific expression of long noncoding RNAs in the mouse brain Proc. Natl. Acad. Sci. 105: 716-721.

Mikkelsen, T.S., Ku, M., Jaffe, D.B., Issac, B., Lieberman, E., Giannoukos, G., Alvarez, P., Brockman, W., Kim, T.K., Koche, R.P., et al. 2007. Genomewide maps of chromatin state in pluripotent and lineage-committed cells. Nature 448: $553-560$.

Perry, R.P., Kelley, D.E., and LaTorre, J. 1974. Synthesis and turnover of nuclear and cytoplasmic polyadenylic acid in mouse L cells. J. Mol. Biol. 82: $315-331$.

Peyman, J.A. 1999. Repression of major histocompatibility complex genes by a human trophoblast ribonucleic acid. Biol. Reprod. 60: 23-31.

Plath, K., Mlynarczyk-Evans, S., Nusinow, D.A., and Panning, B. 2002. Xist RNA and the mechanism of X chromosome inactivation. Annu. Rev. Genet. 36: 233-278.

Prasanth, K.V. and Spector, D.L. 2007. Eukaryotic regulatory RNAs: An answer to the 'genome complexity' conundrum. Genes \& Dev. 21: 11-42.

Prasanth, K.V., Prasanth, S.G., Xuan, Z., Hearn, S., Freier, S.M., Bennett, C.F. Zhang, M.Q., and Spector, D.L. 2005. Regulating gene expression through RNA nuclear retention. Cell 123: 249-263.

Ravasi, T., Suzuki, H., Pang, K.C., Katayama, S., Furuno, M., Okunishi, R., Fukuda, S., Ru, K., Frith, M.C., Gongora, M.M., et al. 2006. Experimental validation of the regulated expression of large numbers of non-coding RNAs from the mouse genome. Genome Res. 16: 11-19.

Saha, S., Murthy, S., and Rangarajan, P.N. 2006. Identification and characterization of a virus-inducible non-coding RNA in mouse brain. $J$. Gen. Virol. 87: 1991-1995.

Sleutels, F., Zwart, R., and Barlow, D.P. 2002. The non-coding Air RNA is required for silencing autosomal imprinted genes. Nature 415: 810-813.

Smetana, K., Steele, W.J., and Busch, H. 1963. A nuclear ribonucleoprotein network. Exp. Cell Res. 31: 198-201.

Spector, D.L. 2001. Nuclear domains. J. Cell Sci. 114: 2891-2893.

Spector, D.L. 2006. SnapShot: Cellular bodies. Cell 127: 1071. doi: 10.1016/ j.cell.2006.11.026.

Waterston, R.H., Lindblad-Toh, K., Birney, E., Rogers, J., Abril, J.F., Agarwal, P., Agarwala, R., Ainscough, R., Alexandersson, M., An, P., et al. 2002. Initial sequencing and comparative analysis of the mouse genome. Nature 420: 520-562.

Willingham, A.T., Orth, A.P., Batalov, S., Peters, E.C., Wen, B.G., Aza-Blanc, P., Hogenesch, J.B., and Schultz, P.G. 2005. A strategy for probing the function of noncoding RNAs finds a repressor of NFAT. Science 309: 1570-1573.

Wilusz, J.E., Freier, S.M., and Spector, D.L. 2008. 3' End processing of a long nuclear-retained noncoding RNA yields a tRNA-like cytoplasmic RNA. Cell 135: 919-932.

Wyers, F., Rougemaille, M., Badis, G., Rousselle, J.C., Dufour, M.E., Boulay, J., Regnault, B., Devaux, F., Namane, A., Seraphin, B., et al. 2005. Cryptic Pol II transcripts are degraded by a nuclear quality control pathway involving a new poly(A) polymerase. Cell 121: 725-737.

Yamada, K., Kano, J., Tsunoda, H., Yoshikawa, H., Okubo, C., Ishiyama, T., and Noguchi, M. 2006. Phenotypic characterization of endometrial stromal sarcoma of the uterus. Cancer Sci. 97: 106-112.

Zhang, Z. and Carmichael, G.G. 2001. The fate of dsRNA in the nucleus: A p5 $4^{\mathrm{nrb}}$-containing complex mediates the nuclear retention of promiscuously A-to-I edited RNAs. Cell 106: 465-475.

Received October 7, 2008; accepted in revised form December 22, 2008. 


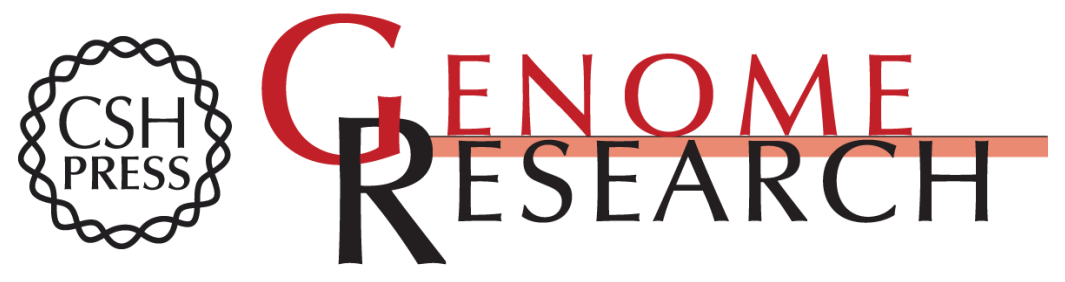

\section{$M E N \varepsilon \beta$ nuclear-retained non-coding RNAs are up-regulated upon muscle differentiation and are essential components of paraspeckles}

Hongjae Sunwoo, Marcel E. Dinger, Jeremy E. Wilusz, et al.

Genome Res. 2009 19: 347-359 originally published online December 22, 2008

Access the most recent version at doi:10.1101/gr.087775.108

Supplemental http://genome.cshlp.org/content/suppl/2009/02/05/gr.087775.108.DC1
Material

References This article cites 49 articles, 14 of which can be accessed free at:

http://genome.cshlp.org/content/19/3/347.full.html\#ref-list-1

License

Email Alerting Receive free email alerts when new articles cite this article - sign up in the box at the Service top right corner of the article or click here.

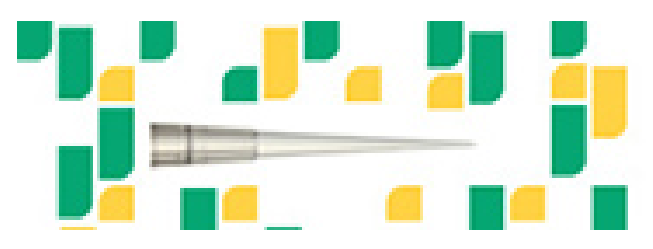

Focused on your science.

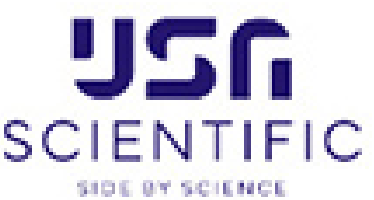

To subscribe to Genome Research go to:

https://genome.cshlp.org/subscriptions 